\title{
The impact of operations and maintenance practices on power plant performance
}

\author{
Dr Shyong Wai Foon
}

Assistant General Manager, (Strategic Management) Strategic Management \& Organizational

Development, Distribution Division, Tenaga Nasional Berhad

Tel: +60379679385, Fax: +60379600340; Email: foonsw@gmail.com

and

\section{Professor Milé Terziovski, PhD}

Curtin Graduate School of Business, Curtin University

Tel: 618 92667900; Fax: 618 92663368; e-mail: mile.terziovski@curtin.edu.au

\begin{abstract}
The aim of the study was to examine the impact of Operations and Maintenance (O\&M) practices, individually and collectively, on power plant performance. Data were collected from more than 100 power plants in Australia and Malaysia. The reliability and validity (content, construct, and criterion) of the practice and performance measures were evaluated. Our study showed that the relationship between O\&M practices and plant performance is significant and positive in a cross-sectional sense. Both people-oriented "soft" as well as technically-oriented "hard" practices were found to be positive and significant predictors of plant performance. This is consistent with literature on socio-technical systems theory that both "soft" and "hard" practices are required to complement each other to produce and sustain high performance. Among the practices, executive commitment and TPM ${ }^{1}$-orientation are the strongest significant predictors of plant performance. Our findings also highlight the impact of maintenance practices on plant performance compared to other practices such as long-term planning, customer focus, knowledge management, and employee involvement. Based on our study we conclude that Total Quality Management (TQM) and maintenance philosophies are sources of sustainable competitive advantage in the power generation sector. The implication of our research findings is that plant managers need to allocate more "softer" resources to the operations and maintenance function if they expect to increase the impact on plant availability.
\end{abstract}

Keywords: TQM, Quality Management, TPM, Operations, Maintenance, power plant

1 TPM stands for Total Productive Maintenance 


\section{Introduction}

The purpose of the restructuring of the electricity supply industry (ESI) was to increase delivery efficiency through market competition (Electricity Supply Association of Australia Limited, 2001; Loredo \& Suarez, 2000; Yokell \& Violette, 1988; Zhang et al., 2004). Restructuring has also introduced new risks for power plant operators. At the operation level, cost, plant reliability and availability, safety, and environmental compliance are important priorities (Draper Jr, 1998; Matusheski, 2000). Plant reliability and availability underpin power plant business performance. Failure of plants to attain high levels of availability can result in significant risks to the plant operators financially. For example, a study conducted recently on one of the thermal power plants in Malaysia found that it had cost its parent company losses amounting to RM175m (AUD\$58m) in lost availability over a period of 2.5 years. It was determined that these losses were a result of poor plant availability. To achieve this objective, relevant plant level O\&M activities should intensify to ensure high plant availability and utilization levels are achieved (Davis, 1995; Desirey, 2000; Moubray, 1997; Swanson, 2001; Tsuchiya, 1992).

However, researchers and industry practitioners have often overlooked the role of equipment effectiveness in operational performance (Fredendall et al., 1997; Nakajima, 1989; Schonberger, 1986). Roth and Miller (1992) asserted that maintenance management might well be the biggest challenge facing power plants in a fiercely competitive market. In order to sustain high plant availability and at the same time meet the cost and regulatory requirements, we contend that appropriate maintenance strategies need to be integrated with other management functions (Nakajima, 1989).

Contributing to this gap in knowledge can assist researchers and practitioners in understanding the role of practices in determining power plant performance as there is now considerable pressure on power plants managers to perform in the competitive deregulated environment (David, 1993; Lindsay \& Peter, 1998). Consequent to the above, we have articulated the research question: Which operations and maintenance practices are critical predictors of plant performance? Answers to the research question would provide a deeper understanding of best predictors of plant performance. This would assist managers to allocate limited resources to those areas, which have the most significant contribution to plant performance. 


\section{Literature review and Theoretical Framework}

We reviewed the literature on TQM and TPM to identify the key variables that should be included in the theoretical framework. The studies that we draw upon for this work were carried out in the past decade. The relationship between total quality management practices and organizational performance has been explored in many empirical studies (Ahire et al., 1996; Black \& Porter, 1996; Flynn et al., 1994; Powell, 1995)). Samson and Terziovski (1999) investigated the relationship using the Malcolm Baldrige National Quality Award (MBNQA) criteria in a large cross-sectional examination of over 1000 manufacturing companies in Australia and New Zealand.

The study found that the seven constructs in the MBNQA criteria were valid and reliable measures of the TQM concept. These constructs are leadership, people, customer focus, strategic planning, information and analysis, process management, and performance. Samson and Terziovski also found that organizational performance is more strongly and significantly predicted by the softer TQM elements of leadership, customer focus, and human resource management. The other three factors (planning, information and analysis, and process management) were found to be insignificant.

This finding is consistent with the conclusion in a study by Ahire et al. (1996) who found that product quality is strongly linked with human resource management, and Powell (1995), who found that competitive advantage is more strongly related to human factors such as executive commitment, open organization, and employee empowerment and less dependable on the techniques and tools of TQM. Other researchers and practitioners have come to realise the importance of maintenance strategy to increase the availability of existing equipment and reduce the need for additional capital investment.

Most of the studies in this area involve the study of the impact of TPM and its implementation on manufacturing performance (Bamber et al., 1999; Brah \& Chong, 2004; Chan et al., 2005; Cooke, 2000; Ireland \& Dale, 2001; McKone \& Weiss, 1998a). Some of these studies were found to have little or no effect on performance (see Cigolini \& Turco, 1997), or that the efficacy of the TPM programme has to be implemented together with other quality improvement programmes like TQM and JIT (McKone et al., 2001). These studies anecdotally claim that an integrated framework incorporating elements from TQM and TPM can assure successful implementation of O\&M strategy and better plant performance. 
We limit the operationalization of the TPM construct to maintenance practices such as prevention maintenance, record keeping, reliability centred maintenance and so on. Other empirical research has also been carried out where the studies consider more than one of the three concepts TQM, JIT, and TPM. There is a general agreement in the literature (McKone et $a l .$, 1999) that TQM, JIT, and TPM constitute quality programmes for performance improvement and are closely interlinked with each other. For example, practices such as committed leadership, customer focus, use of information, and strategic planning are common to TQM and JIT and to some extent, TPM.

We argue that the practices identified as comprising TQM, JIT, and TPM can generally be subdivided into "soft" or people-oriented practices and "hard" or technical-oriented practices. In our study, we measure both "soft" and "hard" practices together and relate them to plant performance. On the performance construct, we incorporate both operational as well as social/regulatory outcomes.

We define "soft" practices as related to leadership, employees, as well as customers. "Hard" practices, on the other hand, concern the techniques, tools, and processes in the organizations, which comprise infrastructure components such as planning, use of information, and maintenance functions. Therefore soft practices are those practices that can lead to the development of an organizational culture to facilitate high performance. Hard factors are associated with processes, tools and techniques used by an organization to attain its objectives.

\section{Theoretical Framework and Hypothesis}

We acknowledge that there will always be debates about what factors to be included into any practices framework. In the context of power plant operations, information gathered from the literature review, and from the work experience of the researchers, we found that practices relating to total quality and maintenance management are actively implemented in most plants. This is not surprising since the introduction of the total quality management concept and the promotion of quality by most governments; quality practices are now widely instituted in most companies (Powell, 1995).

Therefore, we draw from the total quality management literature in order to ascertain which factors we should include in the O\&M framework. These factors are: committed leadership, employee involvement, customer focus, strategic planning, knowledge management, and TPMorientation. Committed leadership, employee involvement and customer focus all involve the 
need for people relationships, and therefore are categorized under the people-oriented soft category.

Conversely, the O\&M factors of strategic planning, knowledge management, and TPMorientation maintenance are more likely to be "mechanistic" or process-based and therefore categorized under the technically-oriented hard category (Tse et al., 2007). Our empirical work aims to validate these factors and determine the relationships between these factors and plant performance. Figure 1 shows the O\&M Practice framework.

\section{$<<<$ Insert figure 1 here $>>$}

\section{Definitions}

In this section, we define the constructs that we have included in the Operations and Maintenance Practice Framework (Figure 1).

\section{Committed leadership}

This factor is considered as one of the key 'drivers' of performance. It examines senior leadership involvement in setting direction for their power plants and creates a culture focusing on customers' requirements (Malcolm Baldrige National Award Criteria, 1994). Leadership also plays a key role in facilitating innovative changes in the power plant work environment; to create a safe and conducive work-place; install a management system supporting the plant's purpose of high performance (Skinner, 2004) through continual learning, employee development, and close sensitivity to the local community and natural environment. In our study, the leadership practices relate to the transformational leadership style (Bass, 1985). The above discussion indicates that committed leadership has a strong influence over plant performance. Therefore, committed leadership is expected to have a significant and positive relationship with plant performance.

\section{Employee involvement}

In our study, we have included employee involvement, as literature on quality and TPM suggests that the participation and commitment of employees bring about improvement in performance (Davis, 1995; Dean \& Bowen, 1994; Nakajima, 1988; Tsuchiya, 1992). Literature on quality suggests that the participation and commitment of all employees are "enabled" to bring about improvement in performance, giving credence to the fact that organizations' greatest assets are in their workforce and the people making up the organizations (Huselid, 1995; Youndt et al., 1996). By enabling them through cross-functional training, empowerment, skills development, use of 
cross-functional teams, and others, their creativity in solving problems and contribution to the achievement of quality as well as plant efficiency can be considered as sources of competitive advantage (Barney, 1991).

Based on the above discussion, a higher level of employee involvement can bring about a greater level of quality and enduring solutions to plant problems. In this way, plant productivity is enhanced and improved. In addition, higher levels of employee involvement create better understanding and a climate of trust in the organization. The construct employee involvement is therefore predicted to have a positive and significant effect on plant performance. Our survey for this factor focuses on such issues as elimination of barriers, evaluation of employee suggestions, empowerment of staff, cross-functional teamwork, and increased autonomy in decision-making.

\section{Customer focus}

The TQM literature asserts that meeting customers' needs is the main purpose of the existence of the organization (Deming, 1982; Imai, 1986; Juran, 1992). It considers the relationship the organization establishes that leads to customer satisfaction, loyalty, and retention (Drucker, 1974) and how the plant manages the customer relationship and communication of the concept of customer to the workforce. The above indicates that the customer focus construct is a key factor in plant performance and is therefore expected to have a positive and significant relationship with plant performance. Measures relating to the customer focus construct include knowing external customers requirements and expectations, customer satisfaction, prompt resolution of customers complaints and problems, and actively responsive to customers' needs.

\section{Strategic planning}

This factor describes the plant's strategic and business planning as well as deployment of plans (Davis, 1995; Evans, 1996). It emphasizes the long range planning, alignment of operational resources with corporate business mission, a process for formal strategic planning, and the extent of the centrality of purpose and mission of the plant within. With respect to power plants, strategic planning provides the link between the present and the future. It also promotes a clear understanding among management and employees of the plant's link to its corporate mission, vision and business strategies, resulting in an alignment of resources internally to attain plant objectives (Ansoff, 1987). Thus, it is expected that this construct will have a positive and significant relationship with plant performance.

\section{Knowledge Management}


The TQM literature suggests that information and data is the 'lifeblood' of the organization (Skinner, 2004), and organizations that collect and analyze information consistently tend to be successful. This factor is concerned with the underlying TQM philosophy that decision-making should be based on facts (Crosby, 1979; Deming, 1982; Feigenbaum, 1991). It involves collection and analysis of data and information about customer needs, operational performance and problems, and feedback on improvement activities or strategies undertaken by the plant, and knowledge of the complexity of the plant operations. Knowledge management enhances the skills and competencies of the employees in the power plants (Deming, 1982; Evans \& Lindsay, 1999). In particular, training and education, which are components of knowledge management, motivate employees to perform better in the belief that the company is investing in them. Overall the employees' capability and hence organizational capability increases, the outcome of which is improved plant performance. Therefore it is predicted that the knowledge management construct is positively and significantly related to plant performance.

\section{TPM-orientation}

This factor is concerned with activities that are responsible for equipment effectiveness. TPM (Swanson, 2001) focuses on the maintenance strategy, the extent of preventive maintenance, the use of root cause analysis for identifying defects and carrying out trouble-shooting activities to bring the plant back to normal operation in the shortest time possible, and keeping and use of records for maintenance analysis as well as carrying out reliability based maintenance activity. High production is assured which in turn motivates plant management to commit more resources such as training and skills development to sustain the TPM program (Senju, 1992). Employees too are motivated to be more involved. Teamwork increases which promotes greater shared responsibility and more ownership of plant problems (Zainal \& Noorliza, 2000). Plant performance increases overall when equipment is better and effectively maintained. Therefore, the TPM-orientation construct is likely to be positively and significantly related to plant performance.

\section{Plant Performance}

Plant performance is measured along dimensions of operational (reliability, capacity utilization) and social/regulatory (environment, community, safety). We have decided to use plant availability, which is an outcome of plant reliability as an indicator for the continual operation and viability of the power plant. All the above performance constructs are measured subjectively. 
Though many researchers argue for a balanced set of financial and non-financial measures to measure performance, there are a number of reasons to opt for subjective operational and social/regulatory data in this study (Kaplan \& Norton, 2006). The main reason for the use of subjective non-financial measures to measure performance was the unwillingness of the deregulated power generation industry players to divulge "sensitive" commercial and financial information ${ }^{2}$. This is especially so with the privately held power companies which comprise a substantial portion of the sample size.

\section{Hypotheses}

This study tests the relationships between the soft factors such as committed leadership, customer focus and employee involvement with plant operational as well as social/regulatory performance. It also tests the relationships between the hard factors such as strategic planning, knowledge management and TPM-oriented with plant operational and social regulatory performance.

Based on the foregoing, our hypotheses examine the relationships and predictive power of both the "soft" and "hard" factors with plant performance. The two hypotheses are:

H1: There is a significant and positive relationship between the people-oriented "soft" factors and overall plant performance.

$\mathrm{H} 2$ : There is a significant and positive relationship between the technically-or processoriented "hard" factors and overall plant performance.

Testing the above hypothesized relationships on the three people-oriented soft factors is important because they provide useful information of their significance in relation to plant performance. In addition, they provide important information on the relative strengths of the three people-related constructs which can be used for comparison with the results of other studies that indicate people-related factors are important sources of competitive advantage (Powell, 1995; Samson \& Terziovski, 1999). Similarly, testing of the hypothesized relationships on technicallyoriented hard constructs provide important information on the effect of technically-oriented O\&M factors on plant performance. Generally there is a lack of empirical studies that incorporate both the social and technological sides of an organization (Cua et al., 2001) where the role of equipment effectiveness is included. By testing the above hypotheses, this study can

\footnotetext{
2 To quote from an industry source in Australia "... the operators are quite 'pathological' about releasing data and information..." (Chong Ong, Head of Victorian SP-Ausnet Network Operation)
} 
show the relative significance and strength of O\&M practices related to equipment performance (Senju, 1992).

\section{Contextual factors}

In order to control for systematic biasing effects, a number of contextual variables are identified and included in this study. By doing so, it is intended to examine whether these contextual variables affect the hypothesized relationships between the O\&M model and plant performance. Such variables that are deemed important are plant size (number of employees) (Ketokivi \& Schroeder, 2004), plant age (Joskow \& Schmalensee, 1987), market environment (Ketokivi \& Schroeder, 2004), and generation technologies (Woodward, 1958). The plant organization size is classified into three categories: (a) small, from one to 19 people, (b) medium, from 20 to 100 people, and (c) large, with more than 100 people. For plant age, we divided the power plants in two groups where one group consisted of those plants with less than 20 years of operation. The other grouped those plants that had been in operation for more than 20 years. The 20th-year period is chosen to demarcate them into new and older plants, and is also the time period for most power purchase agreements, most notably power plants using gas turbine technology. As for market environment, we classified this factor into two classes, that is, regulated and open market. For generation technology, we classified them into the four dominant technologies of conventional thermal, simple cycle gas turbine, combined cycle Gas Turbine /Steam Turbine and hydro.

\section{Methodology and analysis of data}

A mail survey was used to gather data from the power plants located in Malaysia and Australia in order to test the above hypotheses. Power plants in Malaysia and Australia were chosen for study because the restructuring and deregulation of the ESIs in the two countries started at the same time and this would provide a basis for comparison between the two countries. The names and mailing addresses of the power plants in Malaysia and Australia were initially gathered from the lists which appeared in the statistics section of the Energy Commission website (Electricity Supply Department Energy Commission, 2004) and Electricity Supply Association Australia respectively.

\section{Sample Population and Response Rates}

The initial lists identified 63 and 206 plants in Malaysia and Australia respectively. The lists were scrutinized and adjustments made to include only those power plants that were operated 
commercially and subjected to some sort of competitive forces. Plants that were left off included those that were yet to be operational, those that operated singly to provide partial supply to isolated communities, those that were unmanned and remotely operated, experimental plants like solar powered generators, and in-house co-generators. Our sample population includes 'true' power generators that utilize conventional energy conversion technology. Such plants comprise conventional thermal steam plant, combine-cycle power plants, simple cycle gas turbines, reciprocating engines, renewable energy plants (e.g., wind farms), and hydro. The final list produced 42 and 173 individual power plants in Malaysia and Australia respectively.

Mail out of the survey instrument was staggered in two phases. For the first phase, the survey questionnaire was sent to power plants within Malaysia in August 2006. In the second phase, the same survey questionnaire was mailed out to Australian power plants in October 2006. Responses from the two countries were collected over a period of two months each. A total of 108 responses were received, 41 from Malaysia and 67 in Australia. This yielded response rates of 98 percent and 39 percent respectively, giving a total combined response rate of 50 percent. As will be explained and discussed in the data preparation section, these 108 responses formed the data set for all analyses in this study. Managers/team leaders in charge of the plant generating assets or plant operation answered all responses. The respondents were considered to have the necessary experience and knowledge on power plants operations.

\section{Survey Instrument}

The survey instrument was eight pages long. A total of 89 questions were included in the questionnaire. Development of the questions in the survey instrument was carried out by the researchers using a number of sources based on relevant literature in TQM (Ahire et al., 1996; Black \& Porter, 1996; Cua et al., 2001; Powell, 1995; Samson \& Terziovski, 1999), TPM (Brah \& Chong, 2004; Desirey, 2000; McKone et al., 1999; McKone \& Weiss, 1998b) and maintenance (Desirey, 2000). Questions were formulated based on criteria that included The Australian Business Excellence Framework (2004), Malcolm Baldrige National Quality Program Criteria for Performance Excellence (2007) and TNB's AKP Award Criteria (2006). The questionnaire was pre-tested with colleagues and power plant managers in Tenaga Nasional Berhad, Malaysia as well as power plant engineering and management consultants. Changes were made to the questionnaire based on the pre-test feedback. 
There were 59 research questions out of 89 originally selected that were relevant to the research questions associated with this study. These 59 questions were the variables used as inputs for analysis. These variables were assigned to seven constructs as theorized in the O\&M Model: Committed leadership, Customer focus, Employee Involvement, Strategic Planning, Knowledge Management, TPM-orientation, and Performance. Questions were also formulated to provide a description of the power plants and respondents.

\section{Descriptive statistics}

These include the following:.

\section{Profile of respondents}

\section{Respondents' positions in the power plants}

The majority of the respondents were from the plant managers or staffs who were in senior management positions at the power plants. Plants that do not have management positions responded through their officers-in-charge. About $92 \%$ of the respondents were plant managers and managers who hold senior positions in the power plants. These senior positions include operations, maintenance and asset management. Table 1 shows the distribution of respondents according to their positions.

$$
<<<\text { Insert table } 1 \text { here }>>
$$

Many of these managers have years of experience in the power generation industry. Besides being knowledgeable in the technical aspects of running a power plant, they are also involved in managing resources to ensure the viability of the business itself. An analysis of the power plant work experience among the respondents shows that the average work experience was about 22 years. About $80 \%$ of the respondents had ten or more years working in the power generation industry. The highest work experience recorded in the sample data was 45 years. The majority of the respondents, nearly $40 \%$, had between 20 and 30 years work experience in the power generation industry. Thus the survey questionnaire data used for the statistical analysis were the expressed opinions of experienced representatives from the power generation industry in Malaysia and Australia.

\section{Plant organization size (number of employees)}

Following the convention used in most management studies, plant size is classified according to the number of employees. The plant organization size is classified into three categories: (a) small, from one to 19 people, (b) medium, from 20 to 100 people, and (c) large, with more than 100 people. Table 2 shows the distribution of the power plants in the sample data into the three categories. The power plants are found to be distributed equally among the three categories. From the technical aspects, power plant sizes 
can be classified in terms of plant capacity as total installed capacity in megawatts of power. This category of representing plant size is described in the next section.

\section{$<<<$ Insert table 2 here $>$}

\section{Plant size (total installed capacity)}

Total installed capacity measured in megawatts of the power plants in the sample data is shown in figure 2 below. The majority of the power plants in the sample size are sized from 10 megawatts and above. For the sample data in this study, only three power plants were found to have installed capacity of 10 megawatts and less. A check reveals that the three are renewable energy power plants (landfill gas and mini hydro).

$<<<$ Insert figure 2 here $>$

Table 3 shows the number of power plants in each category according to plant installed capacity and number of employees. It shows that large power plants with installed capacities greater than 100 megawatts tend to have more employees (that is, medium to large). However, the indication is that plants with higher installed capacities do not necessary indicate more employees working there. The power generation industry is highly automated, more so in modern plants that were constructed in the last few years. With more competition and privatization, the industry had undergone a change in terms of scale of employment with more emphasis on economic rather than social benefits.

\section{$<<<$ Insert table 3 here $>>$}

The sample data appears to have elicited a good spread of respondents in terms of organization size where the number of power plants is more or less equal in numbers for small, medium and large size categories.

\section{Plant age}

Plant ages are categorised into groups of five years. The distribution is shown in figure 3 below. Most of the power plants in the sample data were relatively new, about $42 \%$ were less than 15 years old. About one quarter had been in operation for more than 30 years. Therefore, it is not unreasonable to say that the sample data contains information on power plants with a relatively wide range of operating ages. For analysis, power plants were divided in two groups where one group consisted of those plants with less than 20 years of operation. The other grouped those plants that had been in operation for more than 20 
years. The 20th-year period is chosen to demarcate them into new and older plants, and is also the time period for most power purchase agreements.

$$
<<<\text { Insert figure } 3 \text { here }>>
$$

The representation of plant age in the statistical data analysis is important as it is theorised as one of the contextual factors which may determine plant performance (Ketokivi \& Schroeder, 2004). Wear and tear, parts deterioration, fatigue and obsolescence are represented by age. There may be differences in efficiency and flexibility between new and old plants. Hence an analysis of plant age is appropriate and in line with the research study.

\section{Location (market environment)}

The power generation industries in both Malaysia and Australia have been opened up to competition, as represented by degree of regulation. Competition in the form of PPA-driven privatization, and thus limited in scope, is found in Malaysia and in the Australian States of Western Australia and Northern Territory. Open competition in the form of market bidding is prevalent in the states of Queensland, New South Wales, Victoria, South Australia and Tasmania. The sample data comprise responses of power plants located in the above-mentioned regions. The distribution of responses from open market and PPA "privatized" market regions was shown in figure 4 below. The number of power plants in open market and PPA-driven privatized market regions was found to be nearly equal in the sample data.

$$
<<<\text { Insert figure } 4 \text { here }>>
$$

\section{Generation technology}

We can classify the generation technologies based on the conversion processes from different energy sources into electrical energy. For this study, they are classified into (a) conventional thermal steam turbine (ST) power plant, (b) simple cycle gas turbine (GT) power plant, (c) combined cycle GT/ST power plant, (d) hydro, (e) wind, and (f) renewables. Figure 5 shows that four major generation technologies constituted more than $80 \%$ of the sample size. These four technologies are the dominant types of generation technologies used by the contemporary power industry.

\section{$<<<$ Insert figure 5 here $>$}

These four dominant technologies of conventional thermal, simple cycle gas turbine, combined cycle GT/ST and hydro are more or less equally represented in numbers in the sample data. Wind and 
renewables constituted about two percent of the sample size. Though these two technologies are emerging in importance with the growing awareness of global warming, they are still at the infancy stage. Thus it is reasonable to suggest that the sample data represents a well balanced mix of the generation technologies normally found in the power generation industry.

In addition, the type of generation technology used is dependent on the availability of fuel resources in the country. Malaysia's generation mix is skewed towards the use of its indigenous gas resources. Australia's plentiful and easily accessible coal reserves in the eastern states of the continent shape its generation mix. Thus we have, in Malaysia the predominant combined cycle gas turbine technology which prevails to capitalize on the gas while the Australia relies very much on the well-proven technology of coal-fired steam turbine technology.

\section{$<<<$ Insert table 4 here $>>$}

Information regarding the prevalence of generation technologies and generation mix is discernible from the sample data. Table 4 illustrates the pattern of generation mix for both Malaysia and Australia. The pattern confirms the generation mix in both countries. The sample data is representative of the generation industry in the two countries in this aspect.

\section{Products and services}

The respondents were requested to list the electricity-related products or services offered by their power plants. The main energy products are (a) base-load energy, (b) intermediate-load energy, and (c) peakload energy. Ancillary services are also offered. These services are to maintain key technical characteristics of the network system. They include services such as (a) spinning or operating reserve $(\text { FCAS })^{3}$, (b) voltage support (NCAS) ${ }^{4}$, and (c) black-start capability. Tables 5 and 6 indicate that number of power plants in sample data that are classified into the various energy products and ancillary services. About $40 \%$ of the power plants concerned are peakers. The remainder is made up of base and intermediate load plants. This is a fair balance of generating assets in any system where peakers and nonpeakers are needed to support a system economically and effectively.

\section{$<<<$ Insert table 5 here $>$}

\footnotetext{
3 Also known as frequency control ancillary services (FCAS).

${ }^{4}$ Also known as network control ancillary services (NCAS).
} 
However, ancillary services in terms of FCAS, NCAS and black-start capability can be supplied by most power plants. These services are as a result of the design and operating philosophies that are incorporated into the power plant during the project development stage. More than $30 \%$ the surveyed plants offered FCAS and NCAS.

\section{$<<<$ Insert table 6 here $>>$}

Base-load and intermediate-load demands are supplied by large conventional thermal and combined cycle power plants where economy of scale in the production of electricity is imperative. Hydro and simple cycle GT power plants fill the slot for peak demand. Characteristics such as quick response in start up and load following inherent in both hydro and simple cycle GT generators fit in nicely with the load demand volatility. Renewable, of course, caters to the base load demand for maximum efficiency (Table 7).

\section{$<<<$ Insert table 7 here $>>$}

The sample data therefore represents a true cross-section of power plants in terms of load demand types. It also presents a picture that is representative of the types of plants in terms of generation technology in line with conventional power generation industry wisdom.

\section{Ownership}

Ownership is defined for this research as state or private. State-ownership here encompasses ownership by utility companies and public, whereas private ownership includes internationally based companies as well. Mixed ownership is the other category and is classified as other. Table 8 shows the distribution of power plant ownership in the sample data.

\section{$<<<$ Insert table 8 here $>>$}

\section{Competitive advantage}

Literature and conventional wisdom in the power generation industry list that the main competitive advantages of power plants are based on their physical attributes. These physical attributes are unit size, number of operating units, low cost of plant maintenance, availability of spares, and last but not least, low or negligible fuel cost (Stoft, 2002).

For this research, power plants respondents were requested to list the advantage of each of the physical attributes mentioned above as compared to their nearest competitors. Table 9 lists the distribution of power plants in terms of physical attributes and perceived competitive advantage as compared to nearest 
competitor. Among the attributes, number of generating units stands out as an important contributing factor in plant competitiveness within the same category. The number of generating units in the plant relates to the flexibility of operation as having more than one generating unit per plant. If one unit is down, the other units can pick up the load demand without shutting down the entire plant. Unit size may have slight competitive advantage. The larger the unit size, the more economical the production is. The other attributes such as low maintenance cost, spares availability, and fuel cost are found to not contribute to competitiveness.

Though cost of fuel constitutes about $70 \%$ of the total generating cost in a conventional power plant (Bureau of Industry Economics, 1992), and thus its impact on any power plant competitiveness is high, the data here suggest that plants in the same category of competition use the same type of fuel. Hence, any competitive advantage in fuel cost is negated. For example, the Victorian power plants use readily available brown coal obtained from the same region. In Malaysia, however, the dominant fuel is natural gas that is supplied by the only national gas supplier at a fixed price.

\section{$<<<$ Insert table 9 here $>$}

Similarly, attributes like spares availability and maintenance cost are not considered as sources of competitive advantage because most of the power plants catering to the specific load demand have generating units of basically the same design and, perhaps, make. The generating equipment market is dominated by the "big five" suppliers - General Electric of the US, Siemens of Germany, the SwissSwedish ABB, the Anglo-French GEC-Alsthom and Mitsubishi Heavy Industries of Japan. These companies control an estimated $76 \%$ of the "new-build" market for fossil- and nuclear-fuelled power station equipment (Financial Times, 1998).

The findings of this subsection implied that in a competitive market, flexibility of operation (number of generating units) and, to a slight extent, unit size, are very important competitive factors especially when operating risks are high, and cost efficiency is a major concern.

\section{Plant availability and capacity utilization}

Last but not least, the survey also requested data on plant performance in terms of plant availability and capacity utilization. As this research also looks into the effects of competition on plant performance in these two measures, the data on power plant from Malaysia and Australia are compared. Deregulation in the power generation industry has stopped at privatization for Malaysia whereas Australia under its National Electricity Market (NEM) has an open wholesale market. Tables 10 and 11 show the distribution of power plants in terms of plant availability and capacity utilization in Malaysia and Australia respectively. 
The findings show that on both scores, there were more power plants in Australia with very high plant availability and capacity factors (for both cases, more than 95\%). High plant availability means that the generating units are always ready to generate. However, Table 11 also shows that power plants in the two countries have an almost similar number of power plants in the high category (more than $91 \%$ for plant availability) comprising about $66 \%$ of Malaysian and $69 \%$ of Australian plants. This indicates that market competition, to certain extent, may have some influence on plant performance in terms of plant availability.

There are, however, a noticeable number of power plants in Australia in this sample data with a capacity factor less than $10 \%$ (Table 12). This indicates that there is a higher incidence of underutilized generating assets in Australia. The present industry structure in the NEM region is such that the portfolio balance of base, intermediate and peaking plants was overweight in base and intermediate sectors. Simhauser (2007), CEO of one of the largest power companies in Australia, pointed out that in his paper presented to an energy conference held in Australia on supply-side portfolio that peaking plants in NEM regions are "drifting further and further away from optimality".

\section{$<<<$ Insert table 10 here $>>$}

It means that there has been a build-up of a number of large conventional base-load steam plants that are modern and more efficient than older plants. As a result, existing but less efficient old thermal plants are pressed to operate in the peaking sector. For example, Queensland has a number of old coal-fired steam plants that on average are operated only during the summer months when demand is high.

On this matter, power plants in Malaysia are better utilized with the majority (45\%) in the 81-95\% capacity factor category. In a PPA-driven environment such Malaysia's, the size, type and location of generating assets are constructed based on detailed feasibility studies on system requirements and on carefully analyzed projected demand and supply. A more conservative approach is therefore taken in this case in deciding the optimal generation portfolio. Productive and allocative efficiencies among the generation portfolio can thus be attained. Productive efficiency refers to the capacity utilization of the generating sector, and allocative efficiency refers to the efficient mix of generating plants that are required to service a region. In the more competitive open market, the construction of power plants is based more on a market approach signalled by electricity market prices. In a commodity-like energy market, business incentive to construct and operate generating plants with large installed capacities and economies of scale to cater to base load demand is high.

$<<<$ Insert table 11 here $>$ 


\section{Synthesis and conclusion of descriptive statistics}

This section has reviewed the survey findings using descriptive statistics where the profiles of the participating power plants were investigated. Supplementary analysis on the competitiveness in terms of the physical attributes and comparison of operational performance of power plants in different market environments was made.

The sample data reveal a cross-section of power generating plants in terms of types of plant size according to number of employees and installed capacities, plant age, generation technologies, ownership, plant location, and products/services offered. Respondents, the majority of whom were in senior management positions, were experienced in power plant operation and management. Thus the information provided was a reflection of their practices in a generally technically complex industry and can be accepted with high confidence.

The electricity industry is very much dependent on the type of natural fuel resources that a country has. Malaysia, which espouses a four-fuel strategy based on coal, natural gas, oil and hydro, is at present very much dependent on natural gas (Electricity Supply Department Energy Commission, 2005) which is more efficiently utilized in the production of electricity from combined cycle gas turbines - hence the prevalence of this type of generation technology in that country.

Conversely, Australia, which is blessed with an abundance of easily accessible and cheap coal deposits, uses coal as the main source of fuel in most of its power plants for electricity production. Other types of fuel used in the generation industry in both countries include hydro and to a certain extent, renewables. The kind of strategic resources in a particular country are reflected in the types of generation used which are thus represented very well in the sample data.

Generation technology, location, plant age and plant size are contextual variables used in the statistical analysis. Location here assumes the role of the competitive environment that is represented by the type of markets, that is, the Malaysian PPA-driven market and Australian open market. Plant age is categorised into two groups. Plant size in terms of the number of employees indicates a close pattern to plant size in terms of installed capacity. In line with extant research, the number of employees is used to represent plant size in this study (Ketokivi \& Schroeder, 2004). Three categories, that is, small, medium and large, are employed for this purpose.

Judging from the operational performance in terms of plant availability and capacity utilization, the differences between the two countries reflect the market environments in which they operate. Though cultures do come into play when comparisons are made between two or more countries, the nature of the power generation industry is such that the work culture emphasis on plant reliability and availability is the same. 
Overall the descriptive findings provide a profile of the industry and general view of the competitiveness in the two electricity wholesale markets. However, what constitutes competitiveness as described here pertains more towards economic factors such as economy of scale, thermal efficiencies and fuel costs. These factors are reflected in the size of power plants, type of generation used, location, and type of loads catered for.

The next sections provide an analysis on the internal factors on power plant performance.

\section{Statistical Data Analysis}

\section{Assessment of non-response bias}

In this study, the technique of wave analysis was used to assess non-response bias (Rogelberg \& Stanton, 2007). This approach compares the survey variables of pre-deadline responses with late responders. As suggested, though, by Rogelberg and Stantion (2007) that this method does not indicate conclusively an absence of bias. Nevertheless, if a difference exists between the two groups, then some degree of nonresponse bias exists.

The data set of power plants from Australia was divided into two groups: pre-deadline and post-deadline. A total of 36 power plants made up the pre-deadline group. Thirty late respondents made up the post deadline group. A number of questions were identified from the survey questionnaire that had high predictive validity and tested for differences between the two groups (independent sample t-test) (Field, 2005). The results of the analysis indicate that there was no significant response bias in the sample concerned.

\section{Incomplete response}

The second stage in the treatment of data was the issue of incomplete responses or missing responses. There were three missing data points in the relevant data set. SPSS MVA (Missing Value Analysis) was used to examine and test for significance of missing data distribution (Tabachnick \& Fidell, 2007). The analysis indicated that the number of missing data in any one variable did not exceed 5 per cent of data missing, and the distribution pattern of missing data was random. Thus, it could be inferred that the 3 missing data were MCAR (missing completely at random). Treatment of missing data includes removing cases or variables with missing data from the analysis, and using an imputation technique (Hair et al., 1998; Tabachnick \& Fidell, 2007). For this study, prior knowledge substitution was used. Tabachnick and Fidell (2007) suggest that this is an effective method when sample size is large and the number of missing values small. It basically involved imputing the missing data with a well-educated guess. This was carried out by identifying and observing the cases (i.e., power plants) with missing data variables and comparing these variables in other similar power plants, which had complete set of data. 


\section{Scanning for outliers}

The third stage of data preparation involved the screening of outliers. This stage also included checking for data normality. Presence of outliers and normality of data usually exist together. All variables in the data set used the 7-point Likert-type interval scale. After appropriate treatment which includes variable transformation (Hair et al., 1998; Tabachnick \& Fidell, 2007) and deletions, skew was still present in eighteen of the variables. The skew ranged from 1.00 to 1.90 . These variables were retained (Hair et al., 1998). Three other variables were heavily skewed ( $\mathrm{z}$-skew=-3.787, -4.319 and -4.541 ) and were removed from further analysis.

\section{Analysis procedures}

The next stage was to carry out a factor analysis of the variables to ensure that they are reliable indicators of the constructs. A cut-off loading of 0.5 was used to screen out variables that were weak indicators of the constructs. (Stevens, 1996, p.371). For this study, Kaiser-Meyer-Olkin measure of sampling adequacy (KMO) was used (see Kaiser, 1970). Kaiser (1974) suggests that samples that have KMO values below 0.5 are unacceptable, between 0.5 and 0.7 as mediocre, between 0.7 and 0.8 as good, between 0.8 and 0.9 as great, and above 0.9 as superb. KMO measure of sampling adequacy for this analysis was greater than 0.8 .

The composite variables derived from the factor analysis formed the independent variables. Six composite variables were identified as independent variables. The dependent variable was the composite performance variable. The identified composite variables were tested for internal reliability for which all were found to have Cronbach's alpha exceeding 0.7 (Nunnally, 1978).

\section{Research Results}

Tables 12 and 13 show the results of factor and reliability analyses. Hair et al. (1998, p.111) informed that the choice of the cut-off factor loading relates to practical and statistical significance. The significance of a factor loading depends on sample size. Stevens (1996) contended that for a sample size of 100 respondents, variables with factor loadings of about 0.5 and higher are significant. For this study, a cut-off loading of 0.50 was used to screen and remove variables that were weak indicators of the constructs.

Of the forty-four variables used for the factor analysis, fifteen variables fail to make the cut-off, leaving twenty-nine variables to constitute the six constructs, which are divided into "soft" and "hard" practices. The six identified constructs are: (1) committed leadership, (2) employee involvement, (3) customer focus, (4) strategic planning, (5) knowledge management, and (6) TPM-orientation. The dependent construct is the nine-item plant performance (Table 14). The reliability values of the six independent and one 
dependent constructs meet or exceed Nunnally's recommended standard (Chronbach Alpha $\geq 0.70$ ) for early stage research (Nunnally, 1978).

\section{$<<<$ Insert Table 12, 13, and 14 here $>>>$}

Table 15 shows the bivariate correlation matrix of the six independent and one dependent variable factors. The result of the correlation analysis is discussed in the following section.

\section{People/customer-oriented "soft" factors and performance}

The results of the bi-variate correlation analysis of this study suggest that "soft" practices are significant and positive in the relationship with plant performance. This is consistent with extant literature in management practices (Powell, 1995; Samson \& Terziovski, 1999). The results of this study suggest that the "soft" practice of committed leadership has the strongest influence on plant performance than employee involvement and customer focus.

\section{Process-oriented "hard" factors and performance}

The "hard" practices indicate moderate to strong and significant correlations with plant performance. Strategic planning had moderate and significant relationships with overall performance $(r=0.445, p<0.01)$. Similarly, the result also indicated moderate and significant correlations between knowledge management systems and overall performance $(\mathrm{r}=0.473, \mathrm{p}<0.01)$. TPM-orientation had moderate to strong and significant relationships with overall performance $(\mathrm{r}=0.548, \mathrm{p}<0.01)$. The results of the bi-variate correlation analysis indicate that "hard" practices factors are significantly albeit with varying strengths related with performance. Of the "hard" practices factors, TPM-orientation is more highly correlated than the other two factors with performance. These results are supported by literature on maintenance practices and manufacturing performance (Brah \& Chong, 2004; McKone et al., 2001).

\section{$<<<$ Insert Table 15 here $\gg>$}

Table 16 shows the multiple regression of the six independent factors regressed on plant performance, F7. Together with the result of the bivariate analysis, the multiple regression analysis is used to test the hypotheses 1 and 2 stated earlier.

$$
<<<\text { Insert Table } 16 \text { here }>>>
$$

\section{Testing of Hypotheses}

Table 16 shows that the linear regression model (adj. $R$ square $=0.470$ ) explains 47.0 percent of the variation in overall plant performance. The result indicates that of the "soft" practices factors, only committed leadership exhibited highly significant and positive relationship with overall plant performance $($ beta $=0.481, \mathrm{t}(101)=4.779, \mathrm{p}<0.001)$. Examination of the correlation matrix in Table 15 shows that the Pearson correlation coefficients between the "soft" practices factors and plant performance are positive and significant. Committed leadership $(r=0.645, p<0.01)$ has the strongest relationship among 
the three "soft" practices, followed by customer focus $(\mathrm{r}=0.450, \mathrm{p}<0.01)$ and employee involvement $(r=0.407, p<0.01)$. Based on the correlation analysis, all three factors are positive and significant in their relationships with overall performance. Therefore, hypothesis $\mathrm{H} 1$ is supported.

The results of the bi-variate correlation analysis (Table 15) indicate that TPM-orientation had a strong and significant correlation with overall plant performance $(\mathrm{r}=0.548, \mathrm{p}<0.001)$, followed by knowledge management systems $(r=0.473, \mathrm{p}<0.001)$ and strategic planning $(\mathrm{r}=0.445, \mathrm{p}<0.001)$. The three factors together (strategic planning, knowledge management systems and TPM-orientation) have a greater explanatory power on overall plant performance. Based on the correlation analysis, all three "hard" factors are positive and significant in their relationship with overall plant performance. Therefore, hypothesis $\mathrm{H} 2$ is supported.

Bi-variate correlation was used in this study to test the linear relationships between variables or factors. This method indicates that if one variable (for example, one of the "soft" or "hard" factors) deviates from its mean the other variable (in this case, performance) is also expected to deviate from its mean in similar manner. Multiple regression analysis tests the relationship between a set of factors in combination together and an outcome which in this case are the sets of "soft" and "hard" factors and the overall plant performance outcome. This statistical technique is based on the assumption of a linear relationship between each independent variable and the dependent variable (Hair et al., 1998). MRA calculates a separate regression coefficient for each independent variable that describes its relationship with the dependent variable. The researcher is then able to evaluate the relative influence of each independent variable from the coefficients (Hair et al., 2003). Hence, the use of MRA here will test the reliability and validity of the O\&M model by testing hypotheses $\mathrm{H} 1$ and $\mathrm{H} 2$.

\section{Validity and reliability}

There is a need to determine whether the constructs of the O\&M model are valid and reliable measures of the underlying practices elements. In other words, they measure what they are intended to measure. Content, construct, and criterion validities are considered (Hair et al., 1998).

\section{Content validity}

A review of appropriate literature of the area of study concern contributed substantially to the content validity of the research. The elements and measurement items that make up the O\&M model selected were based on extensive review of literature on total quality management, human resource practices, and plant maintenance practices. The literature included major national quality awards from Malaysia, Australia, the United States, and Europe. To locate these elements and measurement items within the context of the power generation industry, appropriate literature on economic, public policy, electrical engineering and strategy on regulated and deregulated industries was reviewed as well. Content or face 
validity can be assured when there is widespread agreement generally from among the literature concerned on the various aspects of the area of study. Therefore, it is reasonable to believe that the measures of the O\&M model were considered to have content validity. The items, which were developed from these sources, would clearly define the boundaries and conceptualization of the O\&M model.

\section{Construct validity}

Construct validity is the extent to which an operational measure for a theoretical construct measures the defined construct (Hair et al., 1998; Hair et al., 2003). Two checks are usually used to assess construct validity, that is, convergent and discriminant validity. The construct validity for each of the practice elements was assessed by using Principal Components Factor Analysis (Hair et al., 1998). The items for each of the factors were factor analyzed (using an orthogonal Varimax rotation). Items, which had, factor loadings less than 0.50 were dropped. Convergent validity is then established for all the items loaded onto a particular factor (construct). Discriminant validity is also established as these items already loaded on the particular construct would not represent the other factors (constructs). Tables 12 and 13 show the results of the items and their factor loadings.

\section{Criterion Validity}

Also known as predictive or external validity, criterion validity is concerned with the ability whether the construct(s) performs as expected relative with other variables of the plant performance. The result as shown in Table 16 produces $\mathrm{R}$ equals to 0.707 indicating that the six factors have a reasonably high degree of criterion-related validity when taken together and explain 47 per cent of variance in plant performance. Therefore, the model has strong external validity.

\section{Reliability}

Chronbach's alpha is the most commonly used reliability coefficient to determine the internal consistency of a set of measurement items. Coefficient alpha ranges between the values 0.00 to 1.00 . The SPSS for Windows reliability test software was used to assess separately the internal consistency of each of the factors (constructs). The results of the reliability test are shown in Tables 12 and 13. All constructs had Chronbach's alpha exceeding 0.7 .

\section{Test of Strength of Relationship (adjustment for contextual variables)}

For contextual variables, we make use of multivariate analysis of variance (MANOVA) and MANCOVA to test for strength of relationship. MANOVA is an extension of the analysis of variance (ANOVA). It is used as a replacement for ANOVA when more than one dependent variable exists (Hair et al., 1998). It is a dependence technique that is used to assess the statistical differences between the means of two or more groups. Such groups can, as in this study, include categories on plant size, plant age groups, market 
environment, and technologies. It measures the differences for two or more metric dependent variables based on a set of categorical variables acting as independent variables. In using MANOVA, the dependent variables should be related in some way or there is a theoretical basis to consider them together (Field, 2005). Both ANOVA and MANOVA are used in this study to examine whether any statistical differences were present among the groups on the linear combination of the dependent variables.

A number of statistical tests are available in MANOVA to test for the significance of main effects and interactions. These tests include Wilk's Lambda, Pillai's Trace, Hotelling's Trace, and Roy's largest root. Tabachnick and Fidell (2007) recommend Wilk's Lambda for general use. Tukey's post-hoc test is then employed to pinpoint the significant differences among the groups of the set of variables which are significant in the multivariate test.

Confounding variables are variables that are correlated with the outcome or the dependent variable. These variables are not part of the main experimental manipulation or the study, but nevertheless have an influence on the dependent variable. As such, we need to control or partial out the effect of these variables before any statistical analysis such as analysis of variance is carried out. This process compares the means of several of these variables, but controls for the effect of one or more other variables (Field, 2005).

This adjustment process is called analysis of covariance (ANCOVA) (Hair et al., 1998; Meyer, 1993). ANCOVA is an extension of ANOVA. It enables the researcher to explore the differences between groups while statistically controlling for an additional continuous variable called covariate (Tabachnick \& Fidell, 2007). For a comparison of samples with more than one dependent variable, the multivariate analysis of covariance (MANCOVA) is used. In this study MANCOVA is used to analyze the effects of these variables on the dependent variable. The three soft factors and three hard factors were used as covariates to explore the differences in plant organization size, plant age, market environment and generation technology.

In this study, the following contextual categories are divided into their respective groupings as follow:

(1) plant size: small (1-20 staff), medium (21-100 staff), and large (more than 100 staff) (Feng, 2006)

(2) plant age: group 1 (1-20 years) and group 2 (>20 years)

(3) market environment: group 1 (open) and group 2 (PPA-driven)

(4) generation technology: group1 (steam turbine), group 2 (gas turbine), group 3 (combined cycle), and group 4 (hydro \& others).

Comparison of the two regression equations in Table 16 and 17 indicates that the coefficients of the independent variables have not changed significantly. The independent variables are committed leadership, employee involvement, customer focus, strategic planning, knowledge management and TPMorientation. With reference to Tables 5 and 6 , and comparing the $\mathrm{b}$ and $\mathrm{p}$ values of the estimate fitted 
linear models, the results indicate that there is no significant changes in both the $b$ and $p$ values between the fitted linear models when adjusted for plant size, age, market type and generation technology.

$<<<$ Insert Table 17 here $>>>$

Similarly, adjusted $\mathrm{R}^{2}$ is not changed significantly (adj $\mathrm{R}^{2}$ was 0.470 and 0.472 prior and after adjustment for plant organization size, adj $\mathrm{R}^{2}$ was 0.470 and 0.467 prior and after adjustment for plant organization size, adj $\mathrm{R}^{2}$ was 0.470 and 0.468 prior and after adjustment for market type, adj $\mathrm{R}^{2}$ was 0.470 and 0.523 prior and after adjustment for generation technology respectively). This shows that the explanatory power for plant performance is not changed significantly when the relationship between the O\&M factors and plant performance was adjusted for plant organization size, plant age, market type and generation technology

\section{Discussions of Results}

The results of the regression analysis show that committed leadership (beta=0.481, $\mathrm{t}(101)=4.779$, $\mathrm{p}<0.001)$ and TPM-orientation (beta=0.282, $\mathrm{t}(101)=2.871, \mathrm{p}<0.001$ ) are significant differentiators between high and low performing power plants. The area of research on sustainable competitive advantage for organizations using the resource-based theory, either on TQM (Cua et al., 2001; Powell, 1995), TPM (Brah \& Chong, 2004; Cua et al., 2001), JIT (Cua et al., 2001), or human resource management (Huselid, 1995), have people practices as the basis of their findings or the so-called "soft" practices.

We found that the "hard" TPM-oriented practice of keeping records, total preventive maintenance, and collection and analysis of information, are also significant. High levels of leadership commitment effectively align and focus the available resources in attaining plant operational objectives, and maintenance systems or processes that involve a TPM-orientation efficiently utilize those resources in actively seeking to improve equipment and plant reliability, availability, and efficiency. This tends to produce high overall performance. It underscores the importance that both people-oriented "soft" and process/technical-oriented "hard" practices are required in order to attain high plant performance.

However, among the "soft" and "hard" practices, employee involvement has the lowest correlation with plant performance $(\mathrm{r}=0.407, \mathrm{p}<0.01)$. This contradicts some of the earlier findings that people management score consistently higher than other factors (Powell, 1995; Samson \& Terziovski, 1999). One plausible reason for the contradiction is that power plant is still managed conservatively. Though the industry had been deregulated for about 10 years, 
remnants of the traditional management style still exist. The majority of large power plants are still owned by power utilities or government-linked companies in Malaysia (Electricity Supply Department Energy Commission, 2005), New South Wales or Queensland (Parer, 2002). It is not surprising that plants that have been privatized such as in Victoria have achieved better performance (Tamaschke \& Skoufa, 2007). Tests carried out indicate that there are significant differences in performance means between privatized and utility owned plants in terms of plant reliability ( $\mathrm{t}(3.125), \mathrm{df}(68.527), \mathrm{p}=0.03)$ and safety records $(\mathrm{t}(2.172), \mathrm{df}(66.686), \mathrm{p}=0.033)$. Privatised plants may have greater degree of employee empowerment and involvement than nonprivatised plants.

\section{Conclusion}

The main finding of this study is that effective operations and maintenance of power plants needs to comprise both "soft" and "hard" practices in order to achieve competitive advantage in the deregulated power generation sector. Committed leadership and maintenance oriented towards TPM were found to be the main differentiators between high and low performing plants. We also conclude that the O\&M framework is a valid and reliable model for assessing plant performance. The empirical findings suggest that in addition to quality practices, which tend towards developing the people aspect of the organization, the technical aspect of plant equipment and physical assets should be given equal emphasis.

\section{Implications for Plant Managers}

The implication of our research findings for plant managers is that they need to allocate more "softer" resources to the operations and maintenance function if they expect high plant availability. Apart from capacity, commercial considerations, and fuel cost (David, 1993), O\&M practices are an important differentiating factor in the competitive ESI. One outcome from this study is that more attention should be paid by management to ensuring equipment effectiveness through appropriate maintenance. Literature on maintenance reiterates this point (Desirey, 2000; Fredendall et al., 1997; Lamb, 1996; Moubray, 1997; Yam et al., 2000). Studies conducted on the relationship between the maintenance function and plant

performance consistently point to the important function of maintenance (Brah \& Chong, 2004; Cooke, 2003). In the context of power plant operations, most have implemented quality standards such as the ISO standard series. Yet the effectiveness of ISO certification in power plants in Malaysia and Australia (whether or not it helps them to perform) is still uncertain as indicated by the empirical studies on the manufacturing sector in the two countries (Jabnoun \& Kanapathy, 1998; Terziovski, 1997). 
The findings of this study add to the arguments with the support of hypotheses $\mathrm{H} 1$ and $\mathrm{H} 2$ with potential implications for the national bodies of the two countries which are involved in the promotion of quality management. Hypotheses $\mathrm{H} 1$ and $\mathrm{H} 2$ confirmed that, in addition to the softer dimensions of practices, the harder technically-oriented dimensions of practices related to preventive maintenance are important for operational performance.

The importance of the findings of $\mathrm{H} 1$ and $\mathrm{H} 2$ indicates that a quality framework alone may not be as beneficial as expected for improved plant performance. It may therefore be pertinent to revise the criteria of the national quality awards to include factor(s) concerning equipment effectiveness as one of the core categories for the development of a strong maintenance program to enhance competitiveness and thus significance of the manufacturing sector (Nakajima, 1989). A more effective approach may be the set-up of a national or industry body complementing the quality bodies to be responsible for better equipment management. It is suggested that this new body be involved in promoting and administering a national excellence award for plant maintenance. The Japan Institute of Plant Maintenance (JIPM), which is responsible for the prestigious PM Excellence Award, is one such example that has successfully promoted the development of a maintenance culture in Japan (Senju, 1992).

The value of this finding is all the more important given the capital-intensive and strategic nature of the power generation industry. The increase in plant reliability and thus availability not only assures the authorities of cost-effective electricity but also optimizes the country's generating assets. Optimizing the generating assets can reduce reserve margins thereby saving unnecessary capital expenditures on new power plant built-ups that would not be utilised efficiently (Price, 1999). The case of the current large reserve margins in Malaysia of more than $40 \%$ points to the fact that high plant unavailability in previous years was one of the factors contributing to the overbuilt capacity (Annual Report 2006 Tenaga Nasional Berhad, 2006; Booz Allen \& Hamilton, 1998b).

The confirmation of $\mathrm{H} 1$ and $\mathrm{H} 2$ has implications for plant managers. Hypotheses $\mathrm{H} 1$ and $\mathrm{H} 2$ confirmed that the O\&M model is a valid and reliable measuring instrument for predicting the relationship between O\&M and plant performance. As such, the O\&M model offers a framework for power plants to assess themselves by comparing where they are relative to the "best" O\&M practices. The self-assessment process should then indicate to the plant managers the differences in O\&M practices. It should also indicate as well the efficacy of using a TQM framework for plant improvement as practised by some of the power plants. The self-assessment should enable a plant to identify its strengths and weaknesses so that a strategy can be formulated for improving plant performance (Evans \& Lindsay, 1999).

\section{“Best” practice implementation of $O \& M$}


Most power plants still follow the old traditional hierarchical structure in implementing an effective O\&M policy. However, many plants implemented these changes without credible evidence in terms of which O\&M practices contribute to plant performance, and why and how they contribute to this performance. Thus, the results of the hypotheses $\mathrm{H} 1$ and $\mathrm{H} 2$ have significant implications for power plant managers for the implementation of effective O\&M strategy and methods.

$\mathrm{H} 1$ and $\mathrm{H} 2$ confirm that higher plant performance requires the simultaneous use of soft and hard dimensions of the O\&M leadership and TPM-orientation. These two O\&M factors are better predictors than employee involvement, customer focus, strategic planning, and knowledge management. The finding here would alert managers to the relative importance of plant maintenance practices over other practices associated with long-term planning, customer focus, employee involvement and knowledge management. The influence of the other factors such as employee involvement, customer focus, strategic planning, and knowledge management on plant performance is significant only in their relationships with plant performance individually but not collectively as indicated in the regression result.

The findings also indicate that contextual factors are not strong contributors to plant performance. Nevertheless, the findings indicate that thermal plants that do not have natural constraining elements can have higher performance in terms of capacity utilization than non-thermal plants which depend very much on the natural environment. However, the effect of these contextual factors on the strength of the relationship between O\&M factors and plant performance is not significant. This indicates that internal O\&M factors have more explanatory power on plant performance than contextual factors.

The main implication resulting from this study at all levels is that the traditional O\&M practices that emphasize control and command need to be changed to reflect the current situation following deregulation. Strong people-related practices and a proactive maintenance program that emphasizes preventive maintenance are the two main attributes of an effective O\&M to bring about high power plant performance.

\section{Limitations}

Our research is cross-sectional in nature, therefore, it does not permit us to account for the lag between implementation and performance. This limitation may be overcome by conducting a longitudinal study. Secondly, our performance measures are subjective and may be subject to response bias. Furthermore, the introduction of competition has made the availability of objective data difficult. Third, the number of alternative renewable energy power plants in our sample is low. Renewable energy plants are growing in importance with public and energy policy maker. Further research into this area may reveal other innovative aspects of O\&M practices. 


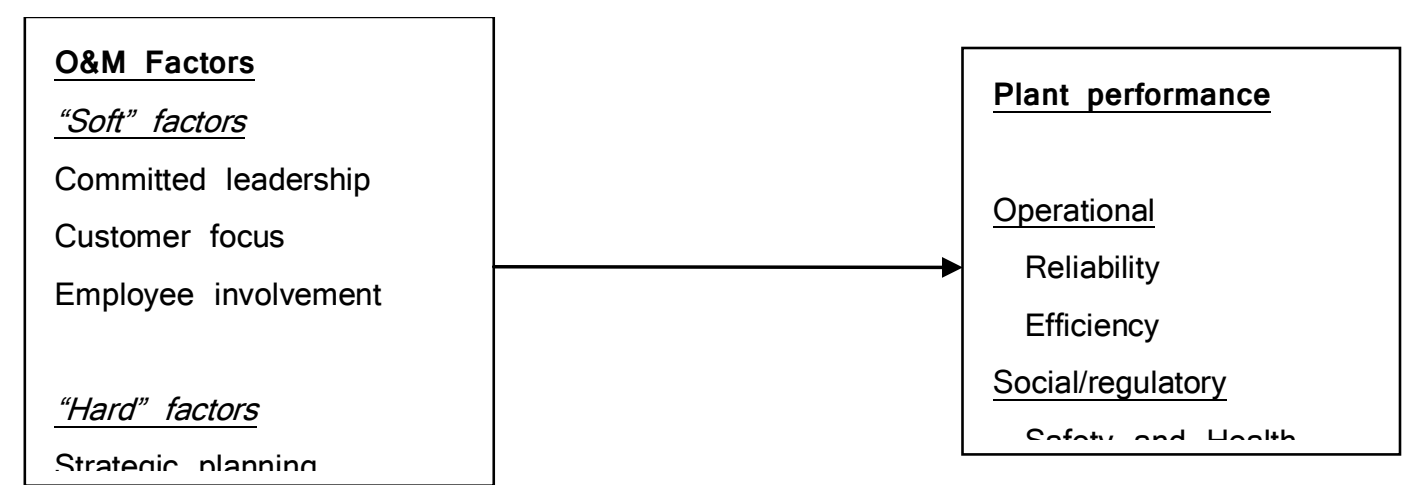

\section{Figure 1 O\&M Practice Framework}

\begin{tabular}{||l|l|l|l||}
\hline \hline No & Positions in Power plant & Number & Percent (\%) \\
\hline 1 & Plant manager & 75 & 70 \\
\hline 2 & Operation manager & 13 & 12 \\
\hline 3 & Maintenance manager & 2 & 2 \\
\hline 4 & Asset manager & 9 & 8 \\
\hline 5 & Officer-in-charge & 9 & 8 \\
\hline \hline
\end{tabular}

Table 1 Respondents' positions in power plants

\begin{tabular}{||l|l|l|l||}
\hline $\begin{array}{l}\text { Plant size according to number of } \\
\text { employees }\end{array}$ & $\begin{array}{l}\text { Small (1 to } \\
\mathbf{1 9})\end{array}$ & $\begin{array}{l}\text { Medium (20 to } \\
\mathbf{1 0 0})\end{array}$ & $\begin{array}{l}\text { Large (more than } \\
\mathbf{1 0 0})\end{array}$ \\
\hline Number in sample data & 35 & 40 & 33 \\
\hline
\end{tabular}

Table 2 Distribution of power plants according to plant organization size 


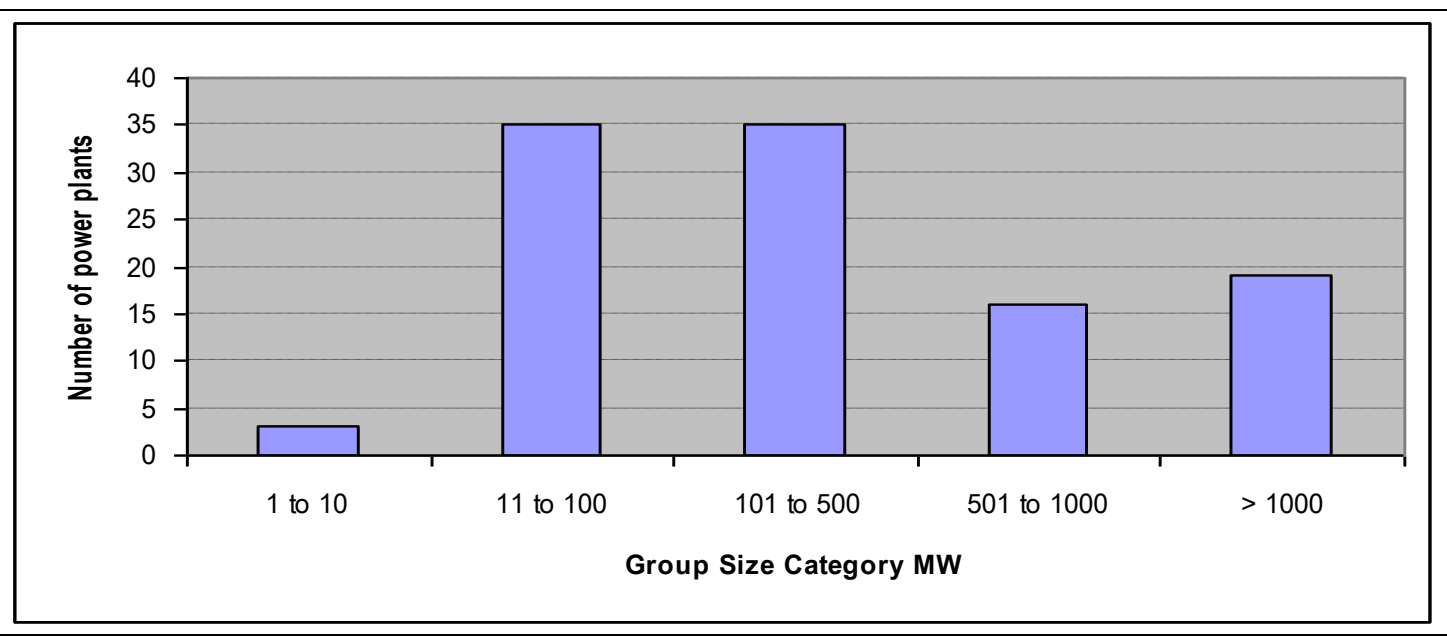

Figure 1 Distribution of power plants by group size (MW)

\begin{tabular}{||l|l|c|c|c|c|c||}
\hline & \multicolumn{7}{|c||}{ Plant group size categories (MW) } \\
\hline $\begin{array}{l}\text { Organization } \\
\text { size (number } \\
\text { of employees) }\end{array}$ & \multicolumn{1}{|c|}{ to 10 } & $\mathbf{1 1}$ to 100 & $\mathbf{1 0 1}$ to 500 & $\mathbf{5 0 1}$ to 1000 & $>\mathbf{1 0 0 0}$ \\
\cline { 2 - 7 } & Small ( 1 to 19) & 3 & 19 & 11 & 2 & 0 \\
\cline { 2 - 8 } & Medium (20 to 99) & - & 14 & 20 & 5 & 1 \\
\cline { 2 - 8 } & Large (>100) & - & 2 & 4 & 9 & 18 \\
\hline
\end{tabular}

Table 3 Cross-tabulation of organization size (number of employees) and plant installed capacity (MW)

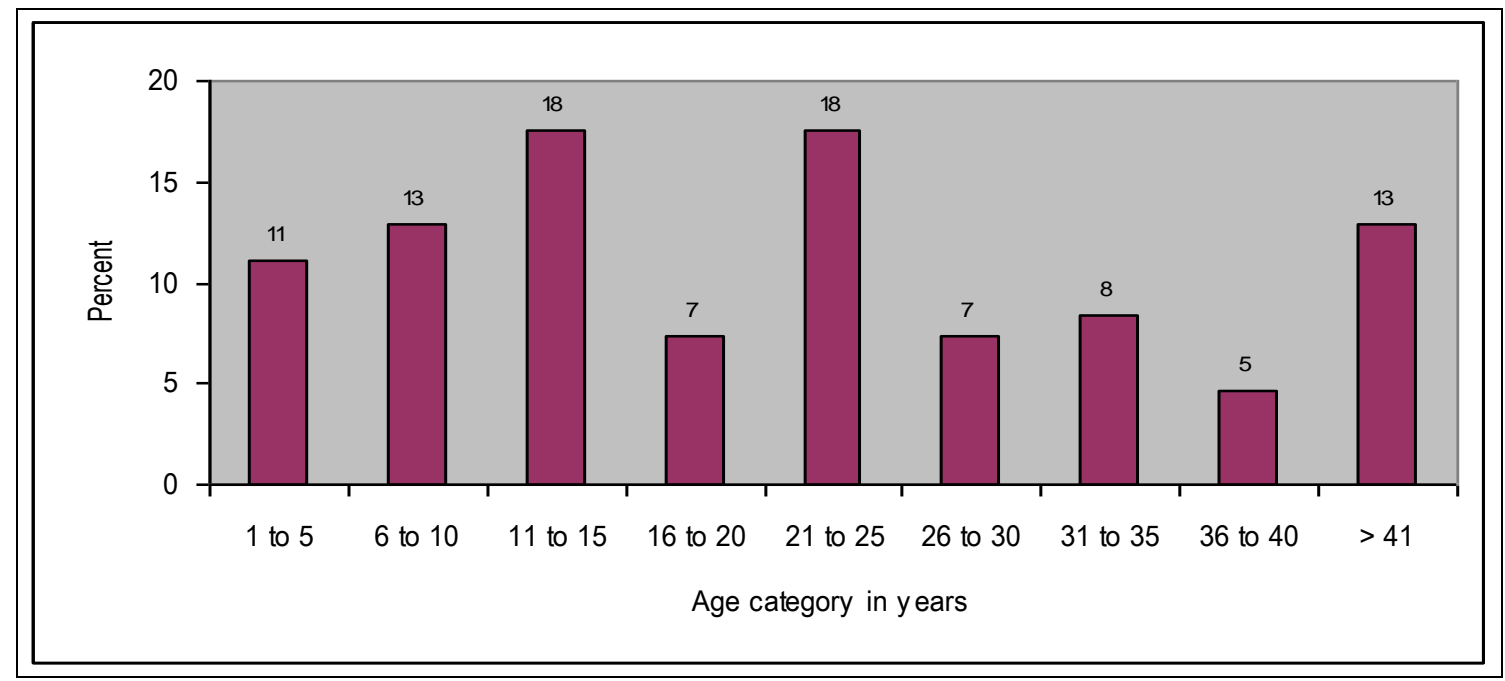

Figure 2 Distribution of power plants according to age category for sample data 


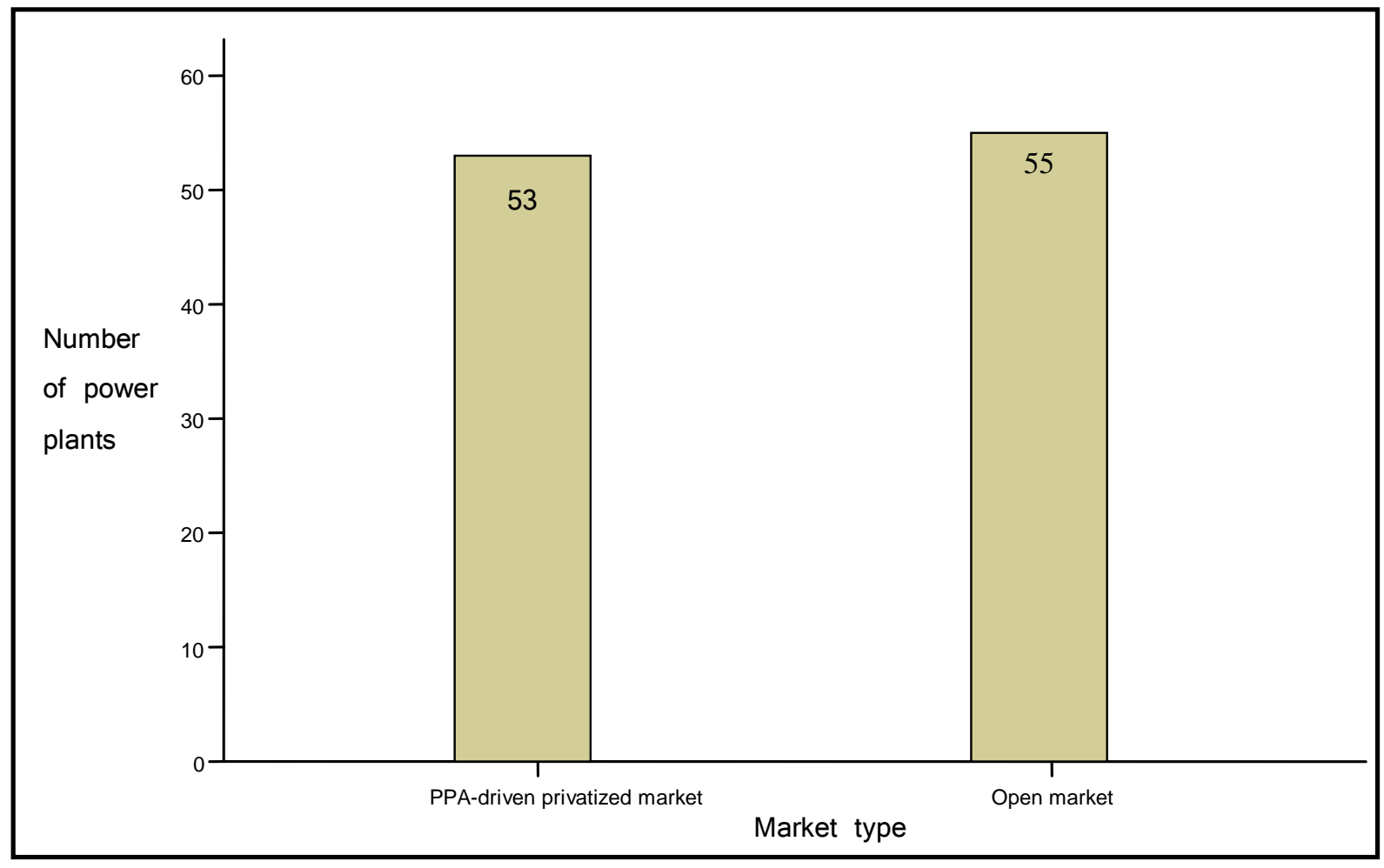

Figure 3 Distribution of power plants in PPA-driven privatized market and open market regions 


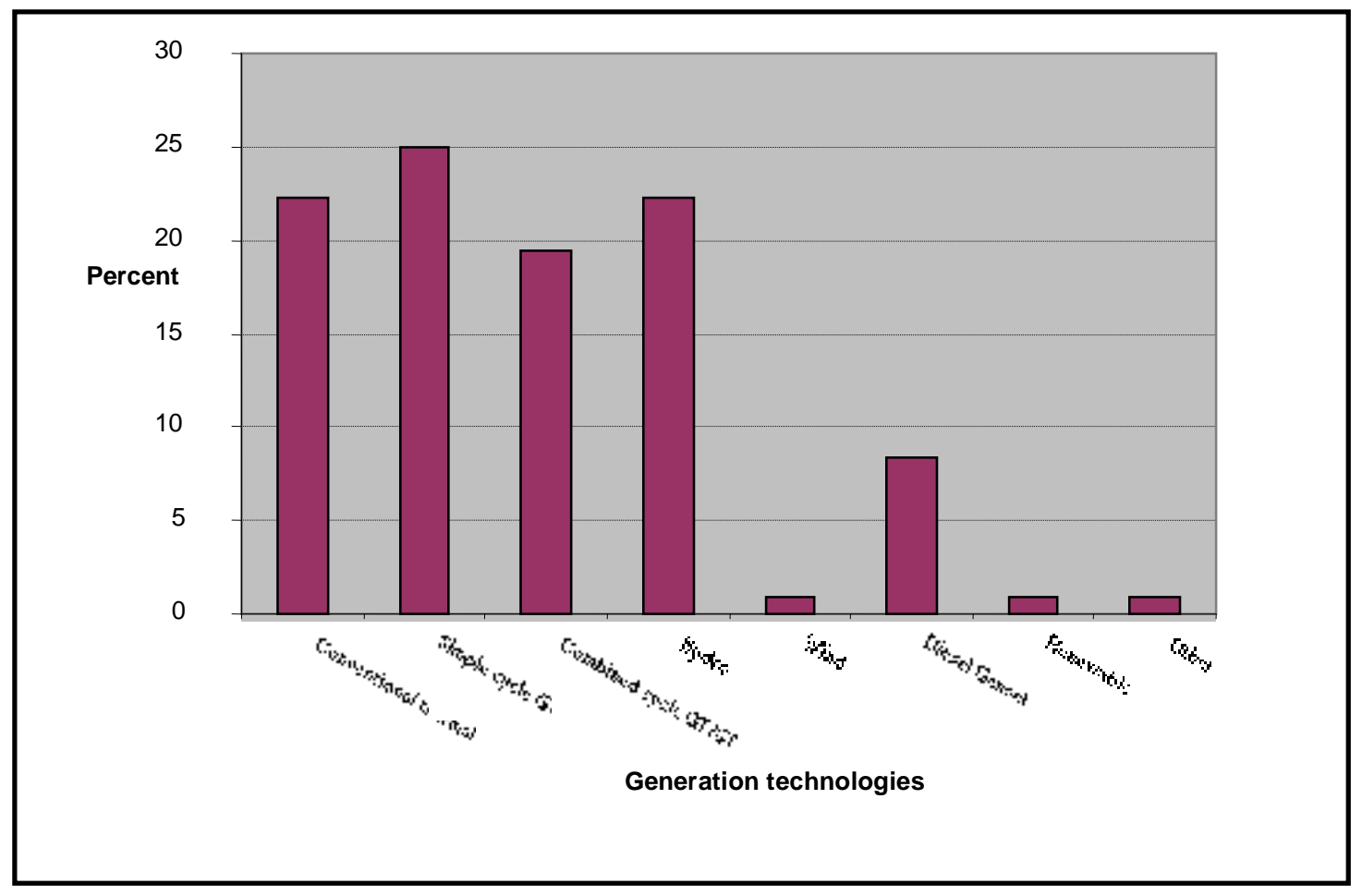

Figure 4 Generation technologies and the distribution in the sample data

\begin{tabular}{||l|l|c|c||}
\hline No & Type of technologies & Malaysia & Australia \\
\hline 1 & Conventional thermal steam turbine & 4 & 20 \\
\hline 2 & Combined cycle gas/steam turbine & 14 & 7 \\
\hline 3 & Simple cycle gas turbine & 6 & 21 \\
\hline 4 & Hydro & 8 & 16 \\
\hline 5 & Diesel genset & 1 & 0 \\
\hline 6 & Renewable & 0 & 67 \\
\hline 7 & Other & 41 & 1 \\
\hline & Total & & \\
\hline
\end{tabular}

Table 4 Distribution of generation technologies by country

\begin{tabular}{||l|l|l||}
\hline Base load plants & Intermediate load plants & Peak load plants \\
\hline 38 & 26 & 44 \\
\hline
\end{tabular}

Table 5 Number of power plants according to plant loads 


\begin{tabular}{|l|l|l|}
\hline FCAS & NCAS & Blackstart \\
\hline 34 & 41 & 64 \\
\hline
\end{tabular}

Table 6 Number of power plants according to ancillary services

\begin{tabular}{||c|c|c|c|c|c|c||}
\hline \hline Type of load & $\begin{array}{c}\text { Conventional } \\
\text { thermal plant }\end{array}$ & $\begin{array}{c}\text { Simple } \\
\text { cycle GT }\end{array}$ & $\begin{array}{c}\text { Combined } \\
\text { cycle GT/ST }\end{array}$ & Hydro & Renewable & $\begin{array}{c}\text { Diesel } \\
\text { genset }\end{array}$ \\
\hline Base load & 13 & 3 & 15 & 3 & 1 & 3 \\
\hline $\begin{array}{c}\text { Intermediate } \\
\text { load }\end{array}$ & 8 & 3 & 6 & 6 & 0 & 3 \\
\hline Peak load & 3 & 20 & 4 & 10 & 0 & 6 \\
\hline
\end{tabular}

Table 7 Cross tabulation of process technology and type of energy products among power plants in sample data

\begin{tabular}{|l|l|l||}
\hline Ownership & Number of power plants & Percent of power plants \\
\hline State-owned & 55 & 51 \\
\hline Privately-owned & 43 & 40 \\
\hline Other & 10 & 9 \\
\hline
\end{tabular}

Table 8 Distribution of power plant ownership in sample data

\begin{tabular}{||l|l|c|c||}
\hline \hline $\begin{array}{l}\text { Physical } \\
\text { attributes }\end{array}$ & $\begin{array}{l}\text { Number of } \\
\text { power plants }\end{array}$ & Percentage \\
\hline Unit size & No competitive advantage & 34 & 32 \\
\cline { 2 - 4 } & Competitive advantage & 36 & 33 \\
\cline { 2 - 4 } & Indifferent & 37 & 34 \\
\hline \multirow{2}{*}{$\begin{array}{l}\text { Number of } \\
\text { generating units }\end{array}$} & No competitive advantage & 30 & 28 \\
\cline { 2 - 4 } & Competitive advantage & 41 & 38 \\
\hline
\end{tabular}




\begin{tabular}{||l|l|c|c||}
\hline \multirow{4}{*}{$\begin{array}{l}\text { Low maintenance } \\
\text { cost }\end{array}$} & Indifferent & 36 & 33 \\
\cline { 2 - 4 } & No competitive advantage & 31 & 29 \\
\cline { 2 - 4 } & Competitive advantage & 35 & 32 \\
\hline \multirow{3}{*}{$\begin{array}{l}\text { Easy availability } \\
\text { of spares }\end{array}$} & No competitive advantage & 36 & 37 \\
\cline { 2 - 4 } & Competitive advantage & 36 & 33 \\
\cline { 2 - 4 } & Indifferent & 35 & 32 \\
\hline Fuel cost & No competitive advantage & 46 & 43 \\
\cline { 2 - 4 } & Competitive advantage & 46 & 14 \\
\cline { 2 - 4 } & Indifferent & 15 & 43 \\
\hline
\end{tabular}

Table 9 Distribution of power plants in terms of physical attributes and perceived competitive advantage as compared to nearest competitor

\begin{tabular}{||l|l|l|l|l|l||}
\hline \multicolumn{2}{|c|}{} & \multicolumn{4}{|c|}{ Country } \\
\hline \multicolumn{2}{|c|}{} & \multicolumn{2}{|c|}{ Malaysia } & \multicolumn{2}{c||}{ Australia } \\
\hline \multirow{4}{*}{$\begin{array}{c}\text { No. of } \\
\text { stations }\end{array}$} & Percentage & $\begin{array}{c}\text { No. of } \\
\text { stations }\end{array}$ & Percentage \\
\hline \multirow{5}{*}{ Availability } & less than 80\% & 9 & 22.0 & 4 & 6.1 \\
\cline { 2 - 7 } & $\mathbf{8 1 - 9 0 \%}$ & 5 & 12.2 & 16 & 24.2 \\
\cline { 2 - 7 } & $\mathbf{9 1 - 9 5 \%}$ & 23 & 56.1 & 18 & 27.3 \\
\cline { 2 - 7 } & more than 95\% & 4 & 9.8 & 28 & 42.4 \\
\cline { 2 - 7 } & Total & 41 & 100.0 & 66 & 100.0 \\
\hline
\end{tabular}

Table 10 Availability factor by country

\begin{tabular}{||l|l|l|l|l|l||}
\hline \multicolumn{2}{|l|}{} & \multicolumn{2}{l|}{ Country } & \multicolumn{2}{l||}{ Australia } \\
\hline \multicolumn{2}{|l|}{} & \multicolumn{2}{l|}{ Malaysia } \\
\hline & $\begin{array}{l}\text { No. of } \\
\text { stations }\end{array}$ & Percentage & $\begin{array}{l}\text { No. of } \\
\text { stations }\end{array}$ & Percentage \\
\hline Capacity factor & less than 10\% & 0 & 0 & 15 & 22.7 \\
\hline & $\mathbf{1 1 - 2 0 \%}$ & 2 & 5.0 & 3 & 4.5 \\
\hline & $\mathbf{2 1 - 4 0 \%}$ & 2 & 5.0 & 6 & 9.1 \\
\hline & $\mathbf{4 1 - 6 0 \%}$ & 6 & 15.0 & 9 & 13.6 \\
\hline & $\mathbf{6 1 - 8 0 \%}$ & 11 & 27.5 & 9 & 13.6 \\
\hline & $\mathbf{8 1 - 9 5 \%}$ & 18 & 45.0 & 11 & 16.7 \\
\hline & more than 95\% & 1 & 2.5 & 13 & 19.7 \\
\hline & Total & 40 & 100.0 & 66 & 100.0 \\
\hline
\end{tabular}

Table 11 Capacity factor by country 


\begin{tabular}{|l|l|}
\hline F1: Committed leadership & Construct reliability, $\alpha=0.719$ \\
\hline ITEM & $\underline{\text { FACTOR LOADINGS }}$ \\
\hline q25- actively encourage change in our plant & 0.513 \\
\hline $\begin{array}{l}\text { q29- environmental (“green') protection issues are proactively } \\
\text { managed at this site }\end{array}$ & 0.572 \\
\hline q66- excellent Occupational Health and Safety practices & 0.552 \\
\hline q26- there is a high degree of unity of purpose throughout our plant & 0.595 \\
\hline & \\
\hline F2: Employee Involvement & Construct reliability, $\alpha=0.826$ \\
\hline$\underline{\text { ITEM }}$ & $\underline{\text { FACTOR LOADINGS }}$ \\
\hline q43- there is increased employee autonomy in decision-making & 0.815 \\
\hline q45- problems solved through small group sessions & 0.761 \\
\hline $\begin{array}{l}\text { q27- we have eliminated barriers between individuals and/or } \\
\text { departments }\end{array}$ & 0.694 \\
\hline q42- all employee suggestions are evaluated & 0.631 \\
\hline q40- cross-functional teams are often used & 0.615 \\
\hline & Construct reliability, $\alpha=0.907$ \\
\hline F3: Customer focus & $\underline{\text { FACTOR LOADINGS }}$ \\
\hline$\underline{\text { ITEM }}$ & 0.861 \\
\hline $\begin{array}{l}\text { q74- our company actively seeks ways to meet customers' } \\
\text { requirements }\end{array}$ & 0.834 \\
\hline $\begin{array}{l}\text { q73- customers' complaints and problems are resolved promptly } \\
\text { and efficiently }\end{array}$ & 0.808 \\
\hline q72- we are customer focused & 0.781 \\
\hline q70- we strive to be highly responsive to our customers & 0.632 \\
\hline q69- know our external customers' & \\
\hline
\end{tabular}

Table 12 Factor analysis: Independent variables (people/customer-oriented "soft" practices)

\begin{tabular}{|l|l|}
\hline F4: Strategic planning & Construct reliability, $\alpha=0.905$ \\
\hline ITEM & FACTOR LOADINGS \\
\hline $\begin{array}{l}\text { q33- our plant has a formal strategic planning process which results } \\
\text { in a written mission, long range goals and strategies for } \\
\text { implementation }\end{array}$ & 0.778 \\
\hline $\begin{array}{l}\text { q34- plant management routinely reviews and updates a long-range } \\
\text { strategic plan }\end{array}$ & 0.722 \\
\hline $\begin{array}{l}\text { q31- we have a written statement of strategy covering all operations } \\
\text { which is clearly articulated and agreed to by our senior plant staff. }\end{array}$ & 0.706 \\
\hline $\begin{array}{l}\text { q30- we have a mission statement which has been communicated } \\
\text { throughout the plant and is supported by our staff }\end{array}$ & 0.589 \\
\hline $\begin{array}{l}\text { q32- plant's operation effectively aligned with corporate business } \\
\text { mission }\end{array}$ & 0.564 \\
\hline & Construct reliability, $\alpha=0.846$ \\
\hline F5: Knowledge management & $\underline{\text { FACTOR LOADINGS }}$ \\
\hline$\underline{\text { ITEM }}$ & 0.731 \\
\hline q39- we have plant-wide training and development process, & \\
\hline
\end{tabular}




\begin{tabular}{|l|l|}
\hline including career path planning, for all our employees & \\
\hline q48- we make use of benchmarking data & 0.688 \\
\hline q47- charts showing plant performance are posted on the plant floor & 0.668 \\
\hline q38- top management is committed to employee training & 0.648 \\
\hline q65- employee satisfaction is formally and regularly measured & 0.635 \\
\hline $\begin{array}{l}\text { q37- ongoing education and training for all employees is } \\
\text { encouraged }\end{array}$ & 0.603 \\
\hline & \\
\hline F6: TPM orientation & Construct reliability, $\alpha=0.816$ \\
\hline ITEM & $\underline{\text { FACTOR LOADINGS }}$ \\
\hline q55- records of maintenance are kept & 0.863 \\
\hline $\begin{array}{l}\text { q56- our plant has established a total preventive maintenance } \\
\text { programme }\end{array}$ & 0.730 \\
\hline q53- preventive maintenance is widely practiced in our plant & 0.567 \\
\hline q50- collect and analyse information on important activities & 0.603 \\
\hline
\end{tabular}

Table 13 Factor analysis: Independent variables (process-oriented "hard" practices)

\begin{tabular}{|l|l|}
\hline F9: Overall plant performance & Construct reliability, $\alpha=0.775$ \\
\hline ITEM & \\
\hline q75- has high success in meeting anti-pollution targets & \\
\hline q76- unplanned outage rate is low \\
\hline q77- plant's unit cost of production has decreased \\
\hline q78- have reduced the number of unit trippings \\
\hline q79- industrial safety record is excellent \\
\hline q80- measures in our plant that always exceed or meet environmental requirements \\
\hline q81- plant was accident-free \\
\hline q82- relationship with our neighbourhood community is excellent \\
\hline q83- plant production of electricity has increased \\
\hline
\end{tabular}

Table 14 Items and reliability: Dependent construct (Plant performance)

\begin{tabular}{|l|l|l|l|l|l|l|l|}
\hline & F1 (IV) & F2 (IV) & F3 (IV) & F4 (IV) & F5 (IV) & F6 (IV) & $\begin{array}{l}\text { F7 } \\
\text { (DV) }\end{array}$ \\
\hline F1: committed leadership & 1 & & & & & & \\
\hline F2: employee involvement & $.596^{* *}$ & 1 & & & & & \\
\hline F3: customer focus & $.538^{* *}$ & $.469^{* *}$ & 1 & & & & \\
\hline F4: strategic planning & $.597^{* *}$ & $.531^{* *}$ & $.580^{* *}$ & 1 & & & \\
\hline F5: knowledge management system & $.490^{* *}$ & $.374^{* *}$ & $.423^{* *}$ & $.659^{* *}$ & 1 & & \\
\hline F6: TPM-orientation & $.492^{* *}$ & $.335^{* *}$ & $.498^{* *}$ & $.607^{* *}$ & $.616^{* *}$ & 1 & \\
\hline F7: Plant performance & $.645^{* *}$ & $.407^{* *}$ & $.450^{* *}$ & $.445^{* *}$ & $.473^{*}$ & $.548^{* *}$ & 1 \\
\hline
\end{tabular}

IV - independent variable ** Correlation significant at the 0.01 level (1-tailed)

DV - dependent variable

Table 15 Correlation matrix of constructs

\begin{tabular}{|l|l|l|l|l|}
\hline Analysis of Variance (ANOVA) & B & Beta & t-test & $\mathrm{p}$ \\
\hline $\begin{array}{l}\text { Dependent variable, F7: Overall plant performance } \\
\text { F(6,101) }=16.802 \text { (Sig. F = 0.000) } \\
\text { Multiple R=0.707, R square=0.500, adj R square=0.470 }\end{array}$ & & & & \\
\hline Intercept & & & & \\
\hline Factor 1: committed leadership & 0.114 & & 4.1095 & 0.000 \\
\hline Factor 2: employee involvement & 0.443 & 0.481 & 4.779 & 0.000 \\
\hline Factor 3: customer focus & 0.021 & 0.025 & 0.271 & 0.787 \\
\hline Factor 4: strategic planning & 0.056 & 0.076 & 0.816 & 0.416 \\
\hline
\end{tabular}




\begin{tabular}{|l|l|l|l|l|}
\hline Factor 5: knowledge management & 0.097 & 0.122 & 1.205 & 0.231 \\
\hline Factor 6: TPM-orientation & 0.228 & 0.282 & 2.871 & 0.005 \\
\hline
\end{tabular}

Table 16 Summary of Regression Analysis on Dependent Variable, F7: Overall Plant performance

\begin{tabular}{|c|c|c|c|c|}
\hline \multicolumn{5}{|l|}{ Parameter estimates } \\
\hline Dependent variable & Parameter & Coefficient B & $\begin{array}{l}\text { Std. } \\
\text { error }\end{array}$ & p \\
\hline Overall plant performance & Intercept & 0.134 & 0.031 & 0.000 \\
\hline \multirow[t]{9}{*}{$R^{2}=0.512 \quad\left(\right.$ Adj $\left.R^{2}=0.472\right)$} & $\begin{array}{l}\text { Committed } \\
\text { leadership }\end{array}$ & 0.451 & 0.093 & 0.000 \\
\hline & $\begin{array}{l}\text { Employee } \\
\text { involvement }\end{array}$ & -0.025 & 0.084 & 0.769 \\
\hline & Customer focus & 0.043 & 0.070 & 0.534 \\
\hline & Strategic planning & -0.070 & 0.084 & 0.410 \\
\hline & $\begin{array}{l}\text { Knowledge } \\
\text { management }\end{array}$ & 0.106 & 0.080 & 0.191 \\
\hline & TPM-orientation & 0.241 & 0.082 & 0.004 \\
\hline & Plant size - small & -0.044 & 0.028 & 0.122 \\
\hline & Plant size -medium & -0.022 & 0.025 & 0.373 \\
\hline & Plant size - large & 0 & & \\
\hline \multicolumn{5}{|l|}{ Parameter estimates } \\
\hline Dependent variable & Parameter & Coefficient B & $\begin{array}{l}\text { Std. } \\
\text { error }\end{array}$ & p \\
\hline Overall plant performance & Intercept & 0.127 & 0.033 & 0.000 \\
\hline \multirow[t]{8}{*}{$R^{2}=0.502 \quad\left(\right.$ Adj $\left.R^{2}=0.467\right)$} & $\begin{array}{l}\text { Committed } \\
\text { leadership }\end{array}$ & 0.451 & 0.093 & 0.000 \\
\hline & $\begin{array}{l}\text { Employee } \\
\text { involvement }\end{array}$ & 0.016 & 0.078 & 0.837 \\
\hline & Customer focus & 0.046 & 0.070 & 0.512 \\
\hline & Strategic planning & -0.099 & 0.082 & 0.230 \\
\hline & $\begin{array}{l}\text { Knowledge } \\
\text { management }\end{array}$ & 0.096 & 0.080 & 0.234 \\
\hline & TPM-orientation & 0.211 & 0.083 & 0.012 \\
\hline & Age (1-20yrs) & -0.015 & 0.021 & 0.462 \\
\hline & Age (>20yrs) & 0 & & \\
\hline Parameter estimates & & & & \\
\hline
\end{tabular}




\begin{tabular}{|c|c|c|c|c|}
\hline Dependent variable & Parameter & Coefficient B & $\begin{array}{l}\text { Std. } \\
\text { error }\end{array}$ & $\mathbf{p}$ \\
\hline Overall plant performance & Intercept & 0.125 & 0.031 & 0.000 \\
\hline \multirow[t]{8}{*}{$R^{2}=0.502\left(\right.$ Adj $\left.R^{2}=0.468\right)$} & $\begin{array}{l}\text { Committed } \\
\text { leadership }\end{array}$ & 0.451 & 0.093 & 0.000 \\
\hline & $\begin{array}{l}\text { Employee } \\
\text { involvement }\end{array}$ & 0.026 & 0.077 & 0.737 \\
\hline & Customer focus & 0.039 & 0.072 & 0.593 \\
\hline & Strategic planning & -0.102 & 0.081 & 0.209 \\
\hline & $\begin{array}{l}\text { Knowledge } \\
\text { management }\end{array}$ & 0.106 & 0.081 & 0.194 \\
\hline & TPM-orientation & 0.211 & 0.082 & 0.011 \\
\hline & Market (PPA) & -0.018 & 0.021 & 0.391 \\
\hline & Market (open) & 0 & & \\
\hline \multicolumn{5}{|l|}{ Parameter estimates } \\
\hline Dependent variable & Parameter & Coefficient B & $\begin{array}{l}\text { Std. } \\
\text { error }\end{array}$ & $\mathbf{p}$ \\
\hline Overall plant performance & Intercept & 0.055 & 0.033 & 0.094 \\
\hline \multirow[t]{10}{*}{$\mathrm{R}^{2}=0.567 \quad\left(\right.$ Adj $\left.\mathrm{R}^{2}=0.523\right)$} & $\begin{array}{l}\text { Committed } \\
\text { leadership }\end{array}$ & 0.401 & 0.094 & 0.000 \\
\hline & $\begin{array}{l}\text { Employee } \\
\text { involvement }\end{array}$ & 0.023 & 0.086 & 0.787 \\
\hline & Customer focus & -0.093 & 0.072 & 0.197 \\
\hline & Strategic planning & -0.035 & 0.084 & 0.678 \\
\hline & $\begin{array}{l}\text { Knowledge } \\
\text { management }\end{array}$ & -0.018 & 0.086 & 0.831 \\
\hline & TPM-orientation & 0.269 & 0.079 & 0.001 \\
\hline & Gen(ST) & 0.103 & 0.028 & 0.000 \\
\hline & Gen(GT) & 0.072 & 0.032 & 0.020 \\
\hline & Gen(CC) & 0.073 & 0.029 & 0.014 \\
\hline & Gen(H\&O) & 0 & & \\
\hline
\end{tabular}

Table 17. Summary of Regression Analysis on Dependent Variable, F7: Overall Plant Performance with contextual variables of Plant size, plant age, market type, and generation technology

\section{References}


Ahire, S., Golhar, D., \& Waller, M. (1996). Development and validation of tqm implementation constructs. Decision Sciences, 27(1), 23-56.

Ansoff, I. (1987). Corporate Strategy (Rev. ed.). London: Penguin Books.

Bamber, C., Sharp, J., \& Hides, M. (1999). Factors affecting successful implementation of total productive maintenance: A uk manufacturing case study perspective. Journal of Quality in Maintenance Engineering, 5(3), 162-181.

Barney, J. (1991). Firm resources and sustained competitive advantage. Journal of Management, 17(1), 99-120.

Bass, B. M. (1985). Leadership and performance beyond expectations. New York: Free Press.

Black, S., \& Porter, L. (1996). Identification of the critical factors of tqm. Decision Sciences, 27(1), 1-21.

Booz Allen \& Hamilton. (1998). Cbps o\&m management: Virtuous cycle. KL: TNB.

Brah, S. A., \& Chong, W. K. (2004). Relationship between total productive maintenance and performance. International Journal of Production Research, 42(12), 2383-2401.

Chan, F., Lau, H., Ip, R., Chan, H., \& Kong, S. (2005). Implementation of total productive maintenance: A case study. International Journal of Production Economics, 95, 71-94.

Cigolini, R., \& Turco, F. (1997). Total productive maintenance practices: A survey in italy. Journal of Quality in Maintenance Engineering, 3(4), 259-272.

Cooke, F. L. (2000). Implementing tpm in plant maintenance: Some organisational barriers. The International Journal of Quality \& Reliability Management, 17(9), 1003.

Cooke, F. L. (2003). Plant maintenance strategy: Evidence from four british manufacturing firms. Journal of Quality in Maintenance Engineering, 9(3), 239.

Crosby, P. B. (1979). Quality is free. New York: McGraw-Hill Book Company.

Cua, K. O., McKone, K. E., \& Schroeder, R. G. (2001). Relationships between implementation of tqm, jit, and tpm and manufacturing performance. Journal of Operations Management, 19, 675-694.

Dangayach, G., \& Deshmukh, S (2001). Manufacturing strategy: Literature review and some issues. International Journal of Operations and Production Management, 217(7), 884-932

David, A. K. (1993). Competitive bidding in electricity supply. Paper presented at the IEE Proceedings-C.

Davis, F. E. (1995). Best practice awareness. North Strathfield NSW: Rollocorp.

Dean, J. W., Jr., \& Bowen, D. E. (1994). Management theory and total quality: Improving research and practice through theory development. The Academy of Management Review, 19(3), 392-418.

Deming, W. E. (1982). Out of crisis. Cambridge, Mass.: Massachusetts Institute of Technology.

Desirey, S. T. (2000). Positioning maintenance as a competitive advantage. Plant Engineering, 54(5), 66.

Draper Jr, E. L. (1998). Assessment of deregulation and competition. In A. All engineers dinner at American Power Conference (Ed.). Chicago: IEEE Power Engineering Review.

Drucker, P. F. (1975). The practice of management. London: William Heinemann.

Electricity Supply Association of Australia Limited. (2001). Electricity australia 2001 (No. 54th): ESAA. 
Electricity Supply Department Energy Commission. (2004). Statistics of electricity supply industry in malaysia year 2004 edition. KL: Energy Commission.

Evans, J. R. (1996). Leading practices for achieving quality and high performance. Paper presented at the Benchmarking for Quality Management \& Technology.

Feigenbaum, A. V. (1991). Total quality control (3rd, revised ed.). New York: McGraw-Hill Inc.

Feng, M. (2006). The relationship between motivation and effort in the implementation of ISO management systems and organizational performance. Melbourne: University of Melbourne.

Field, A. (2005). Discovering statistics using spss (2nd ed.). London: Sage Publications.

Flynn, B. B., Schroeder, R. G., \& Sakakibara, S. (1994). A framework for quality management research and an associated measurement instrument. Journal of Operations Management, 11(4), 339-366.

Fredendall, L. D., Patterson, J. W., William, J. K., \& Tom, G. (1997). Maintenance: Modeling its strategic impact. Journal of Managerial Issues, 9(4), 440.

Guadagnoli, E., \& Velicer, W. F. (1988). Relation of sample size to the stability of components patterns. Psychological Bulletin, 103(2), 265-275.

Hair, J. F., Anderson, R. E., Tatham, R. L., \& Black, W. C. (1998). Multivariate data analysis (Fifth ed.). London/Sydney/New Dehli: Prentice Hall International.

Hair, J. F., Babin, B., Money, A. H., \& Samouel, P. (2003). Essentials of business research methods: Wiley.

Huselid, M. A. (1995). The impact of human resource management practices on turnover, productivity, and corporate financial performance. Academy of Management Journal, 38(3), 635.

Imai, M. (1986). Kaizan: The key to japan's competitive success. New York: Random House Business Division.

Ireland, F., \& Dale, B. (2001). A study of total productive maintenance implementation. Journal of Quality in Maintenance Engineering, 7(3), 183-191.

Joskow, P. L., \& Schmalensee, R. (1987). The performance of coal-burning electric generating units in the United States: 1960-1980. Journal of Applied Econometrics, 2(2), 85-109.

Juran, J. M. (1992). Juran on quality by design. New York: The Free Press.

Kaiser, H. F. (1970). A second generation little jiffy. Psychometrika, 35(4), 401-415.

Kaiser, H. F. (1974). An index of factorial simplicity. Psychometrika, 39(1), 31-36.

Kaplan, R. S., \& Norton, D. P. (2004). Strategy maps: Converting intangible assets into tangible outcomes. Boston: Harvard Business School Press.

Kass, R., \& Tinsley, H. (1979). Factor analysis. Journal of Leisurre Research, 11, 120-138.

Ketokivi, M., \& Schroeder, R. (2004). Manufacturing practices, strategic fit and performance: A routine-based view. International Journal of Operations and Production Management, 24(2), 171-191.

Lamb, R. G. (1996). Plant availability performance: The missing player in manufacturing competitiveness. IIE Solutions, $28(1), 34$.

Lawrence, P. R., \& Lorsch, J. W. (1986). Organization and environment: Managing differentiation and integration (Rev. ed.). Boston: Harvard Business School Press.

Lindsay, N., \& Peter, J.D. (1998). Electricity industry reform: A case analysis in Australia. Journal of Organizational Change Management, 11(6), 481. 
Loredo, E., \& Suarez, E. (2000). Privatisation and deregulation: Corporate governance consequences in a global economy. Corporate Governance, $8(1), 65-74$.

MacCallum, R. C., Widaman, K. F., Zhang, S., \& Hong, S. (1999). Sample size in factor analysis. Psychological Methods, 4(1), 84-99.

Malcolm Baldrige National Award Criteria. (1994). Malcolm baldrige national award criteria. Washington DC: United States Department of Commerce, National Institute of Standards and Technology.

Matusheski, R. (2000, July 23-26). Analytical methods for plant efficiency and reliability improvements. Paper presented at the 2000 International Joint Power Generation Conference, Miami Beach, Florida.

McKone, K. E., Schroeder, R. G., \& Cua, K. O. (1999). Total productive maintenance: A contextual view. Journal of Operations management, 17(2), 123-144.

McKone, K. E., Schroeder, R. G., \& Cua, K. O. (2001). The impact of total productive maintenance practices on manufacturing performance. Journal of Operations Management, 19, 39-58.

McKone, K. E., \& Weiss, E. N. (1998a). Total productive maintenance: Bridging the gap between practice and research. Production and Operations Management, 7(4), 335351.

McKone, K. E., \& Weiss, E. N. (1998b). Tpm: Planned and autonomous maintenance: Bridging the gap between practice and research. Production and Operations Management, 7(4), 335-351.

Moubray, J. (1997). Reliability-centred maintenance rcm ii (2nd ed.). Oxford: ButterworthHeinemann.

Nakajima, S. (1988). Introduction to tpm. Cambridge MA: Productivity Press.

Nakajima, S. (Ed.). (1989). Tpm development program: Implementing total productive maintenance. Cambridge, Mass.: Productivity Press.

NIST. (2007). Criteria for performance excellence: National Institute of Standards and Technology.

Nunnally, J. C. (1978). Psychometric theory (2nd ed.). New York: McGraw-Hill.

Parer, W. R. (2002). Towards a truly national and efficient energy market. Canberra: Council of Australian Governments Energy Market Review.

Powell, T. C. (1995). Total quality management as competitive advantage: A review and empirical study. Strategic Management Journal, 16(1), 15-37.

Rogelberg, S., \& Stanton, J. M. (2007). Introduction: Understanding and dealing with organizational survey nonresponse. Organizational Research Methods, 10(2), 195-209.

Samson, D., \& Terziovski, M. (1999). The relationship between total quality management practices and operational performance. Journal of Operations Management, 17, 393409.

Schonberger, R. J. (1986). World class manufacturing: The lessons of simplicity applied. London: Collier Macmillan Publishers.

Senju, S. (1992). TQC and TPM. Tokyo: Asian Productivity Organization.

Skinner, A. (2004). The Australian business excellence framework. Sydney: SAI Global.

Stevens, J. (1996). Applied multivariate statistics for the social sciences (3rd ed.). NJ: Hillsdale.

Swanson, L. (2001). Linking maintenance strategies to performance. International Journal of Production Economics, 70, 237-244. 
Tabachnick, B. G., \& Fidell, L. S. (2007). Using multivariate statistics (5th ed.). New York: Harper \& Row.

Tamaschke, R., \& Skoufa, L. (2007). Strategy in a restructured industry environment: The case of electricity generation firms. Paper presented at the 5th ANZAM Operations Management Symposium and 1st Asia Pacific Operations Management Symposium, Melbourne.

Tenaga Nasional Berhad. (2006). Akp award criteria. KL.

Tse, E., Cainey, A., \& Haddock, R. (2007). Evolution on the global stage. Strategy + Business.

Tsuchiya, S. (1992). Quality maintenance: Zero defects through equipment management. Cambridge, MA: Productivity Press.

Woodward, J. (1958). Management and technology. London: HMSO.

Yam, R. C. M., Tse, P., Ling, L., \& Fung, F. (2000). Enhancement of maintenance management through benchmarking. Journal of Quality in Maintenance Engineering, 6(4), 224-240.

Yokell, M. D., \& Violette, D. M. (1988). Market structure and opportunities in the electric utility industry today. Public Utilities Fortnightly, 121(1), 9.

Youndt, M. A., Snell, S. A., Dean, J. W., Jr., \& Lepak, D. P. (1996). Human resource management, manufacturing strategy, and firm performance. Academy of Management Journal, 39(4), 836

Zainal, A. A., \& Noorliza, K. (2000). Quality practices that pay: Empowerment and teamwork. Malaysian Management Review, 35(2)

Zhang, Y.-F., Parker, D., \& Kirkpatrick, C. (2004). Electricity sector reform in developing countries: An econometric assessment of the effects of privatization, competition and regulation. Centre on Regulation and Competition Working paper series (paper no. 62)(Paper no 62). 


\section{Appendix}

\section{SURVEY QUESTIONNAIRE}

THE RELATIONSHIP BETWEEN MANAGEMENT PRACTICES AND PERFORMANCE OF POWER

GENERATION PLANTS

\section{Management Practices Framework}

\begin{tabular}{|l|}
\hline \multicolumn{1}{|c|}{ Management Practices } \\
\hline Committed leadership \\
Strategic Planning \\
Training \\
Employee Involvement \\
Information and Feedback \\
Planned Maintenance \\
Open culture \\
People Management \\
Customer focus \\
\hline
\end{tabular}

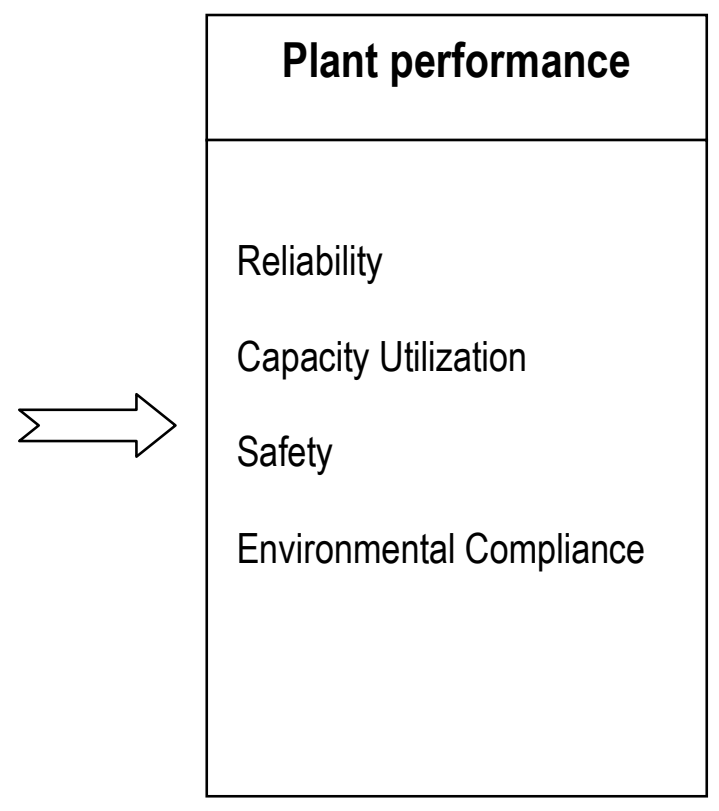




\subsection{BASIC PLANT DATA}

\section{BACKGROUND INFORMATION}

1. Name of power plant (or hydro scheme):

2. Please circle the number that best indicates the ownership of this plant. (Circle all that apply)

\begin{tabular}{|c|c|c|c|c|}
\hline $\mathbf{1}$ & $\mathbf{2}$ & $\mathbf{3}$ & $\mathbf{4}$ & $\mathbf{5}$ \\
\hline Utility-owned & $\begin{array}{c}\text { Publicly- } \\
\text { owned }\end{array}$ & $\begin{array}{c}\text { Privately- } \\
\text { owned }\end{array}$ & $\begin{array}{c}\text { Foreign- } \\
\text { owned }\end{array}$ & $\begin{array}{c}\text { Other: } \\
\text { (Please specify) }\end{array}$ \\
\hline
\end{tabular}

3. How many employees work at your plant presently?

4. What is the estimated age of your oldest power generating plant assets at this site? years

\section{PLANT CHARACTERISTICS}

1. Indicate the MAJOR power generating technology found at your plant.

(Please circle the relevant number in the boxes. You can circle more than once)

\begin{tabular}{|l|l|l|l|l|l|l|l|}
\hline \multicolumn{1}{|c|}{$\mathbf{1}$} & \multicolumn{1}{c|}{$\mathbf{2}$} & $\mathbf{3}$ & $\mathbf{4}$ & $\mathbf{5}$ & $\mathbf{6}$ & $\mathbf{7}$ & \multicolumn{1}{c|}{$\mathbf{\mathbf { 7 }}$} \\
\hline $\begin{array}{l}\text { Conventional } \\
\text { thermal } \\
\text { steam } \\
\text { turbine }\end{array}$ & $\begin{array}{l}\text { Simple } \\
\text { Cycle Gas } \\
\text { turbine }\end{array}$ & $\begin{array}{l}\text { Combined } \\
\text { Cycle Gas } \\
\text { Turbine }\end{array}$ & Hydro & $\begin{array}{l}\text { Wind } \\
\text { power }\end{array}$ & $\begin{array}{l}\text { Renewable } \\
\text { (biomass } \\
\text { /landfill } \\
\text { gas) }\end{array}$ & Diesel & Other: \\
\hline
\end{tabular}

2. Number of units and installed capacities of your plant. (Please circle the appropriate number)

a. Unit capacity (MW)

\begin{tabular}{|c|l|l|l|l|l|c|}
\hline $\mathbf{1}$ & $\mathbf{2}$ & $\mathbf{3}$ & $\mathbf{4}$ & $\mathbf{5}$ & $\mathbf{6}$ & $\mathbf{7}$ \\
\hline $\begin{array}{c}\text { Less than 1 } \\
\text { MW }\end{array}$ & $\begin{array}{l}\text { Between 1 MW } \\
\text { and 10MW }\end{array}$ & $\begin{array}{l}\text { Between 11MW } \\
\text { and 50MW }\end{array}$ & $\begin{array}{l}\text { Between 51MW } \\
\text { and 100MW }\end{array}$ & $\begin{array}{l}\text { Between 101MW } \\
\text { and 150MW }\end{array}$ & $\begin{array}{l}\text { Between 151MW } \\
\text { and 200MW }\end{array}$ & $\begin{array}{c}\text { More than } \\
200 \mathrm{MW}\end{array}$ \\
\hline
\end{tabular}

b. Number of generating units in your plant (or hydro scheme) 


\begin{tabular}{|c|c|c|c|c|c|c|}
\hline $\mathbf{1}$ & $\mathbf{2}$ & $\mathbf{3}$ & $\mathbf{4}$ & $\mathbf{5}$ & $\mathbf{6}$ & $\mathbf{7}$ \\
\hline \multirow{2}{*}{ One } & Between 2 and 4 & Between 5 and 7 & Between 8 and 10 & $\begin{array}{c}\text { Between 11 and } \\
15\end{array}$ & $\begin{array}{c}\text { Between 15 and } \\
20\end{array}$ & More than 20 \\
\hline
\end{tabular}

c. Total plant capacity at your site

\section{MW}

\section{GEOGRAPHICAL LOCATION}

1. Please indicate the following regions within which your power plant is located.

(Please TICK ONE only)

\begin{tabular}{|c|c|c|c|c|c|}
\hline $\mathbf{1}$ & $\mathbf{2}$ & $\mathbf{3}$ & $\mathbf{4}$ & $\mathbf{5}$ & $\mathbf{6}$ \\
\hline $\begin{array}{c}\text { Northern (for West } \\
\text { Malaysia) }\end{array}$ & $\begin{array}{c}\text { Central (for West } \\
\text { Malaysia) }\end{array}$ & $\begin{array}{c}\text { Eastern (for West } \\
\text { Malaysia) }\end{array}$ & $\begin{array}{c}\text { Southern (for West } \\
\text { Malaysia) }\end{array}$ & Sarawak & Sabah \\
\hline
\end{tabular}

\section{MARKET SEGMENT}

Please circle one number against each statement where:

1 = "Strongly disagree", 2 = "Moderately disagree", 3 = "Mildly disagree", 4 = "Neither agree nor disagree", 5= "Mildly Agree", 6 = "Moderately agree" and 7 ="Strongly agree"

1. The following statements relate to the Major location characteristics of your power plant.

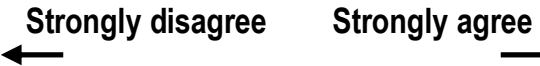

a. Our plant is located near load centres

b. Our plant is located at present site primarily due to engineering requirements (such as adequate land, cooling water, environmental factors)

c. Our plant is located at present site primarily because of easy access to fuel or natural renewable sources

2. The following statements relate to the operational characteristics of your power plant.

a. Our plant generates base load energy most of the time

$\begin{array}{lllllll}1 & 2 & 3 & 4 & 5 & 6 & 7\end{array}$

b. Our plant generates semi-base load energy most of the time

c. Our plant generates peak load energy most of the time

$\begin{array}{lllllll}1 & 2 & 3 & 4 & 5 & 6 & 7 \\ 1 & 2 & 3 & 4 & 5 & 6 & 7\end{array}$


$\begin{array}{ll}\text { d. } & \text { Our plant regularly provides spinning and operating reserve } \\ \text { e. Our plant is regularly requested to support system voltage } \\ \text { f. Our plant has blackstart capability } \\ \text { g. }\end{array}$

$\begin{array}{lllllll}1 & 2 & 3 & 4 & 5 & 6 & 7 \\ 1 & 2 & 3 & 4 & 5 & 6 & 7 \\ 1 & 2 & 3 & 4 & 5 & 6 & 7 \\ 1 & 2 & 3 & 4 & 5 & 6 & 7\end{array}$

3. Relative to our closest competitors, our plant has an advantage in:

$\begin{array}{lllllllll}\text { a. } & \text { Unit size (installed capacity per unit) } & 1 & 2 & 3 & 4 & 5 & 6 & 7 \\ \text { b. } & \text { Number of operating units in our plant } & 1 & 2 & 3 & 4 & 5 & 6 & 7 \\ \text { c. } & \text { Low plant maintenance cost } & 1 & 2 & 3 & 4 & 5 & 6 & 7 \\ \text { d. } & \text { Spare parts availability } & 1 & 2 & 3 & 4 & 5 & 6 & 7 \\ \text { e. } & \text { Low or nil fuel cost } & 1 & 2 & 3 & 4 & 5 & 6 & 7\end{array}$




\section{$\underline{2.0}$ MANAGEMENT PRACTICES}

For questions 2.1 to 2.9 below, please circle the number which best describes your plant's PRESENT position where:

1 = "Strongly disagree", 2 = "Moderately disagree", 3 = "Mildly disagree", 4 = "Neither agree nor disagree", $5=$ "Mildly Agree", 6 = "Moderately agree" and 7 ="Strongly agree"

\subsection{COMMITTED LEADERSHIP}

\section{Strongly disagree Strongly agree}

a. Senior plant management staffs actively encourage change in our plant

b. There is a high degree of unity of purpose throughout our plant

c. We have eliminated barriers between individuals and /or departments.

d. At this plant we proactively pursue continuous improvement rather than reacting to crisis/"fire-fighting"

e. $\quad$ Environmental ("green") protection issues are proactively managed at this site

$\begin{array}{lllllll}1 & 2 & 3 & 4 & 5 & 6 & 7 \\ 1 & 2 & 3 & 4 & 5 & 6 & 7 \\ 1 & 2 & 3 & 4 & 5 & 6 & 7 \\ 1 & 2 & 3 & 4 & 5 & 6 & 7 \\ 1 & 2 & 3 & 4 & 5 & 6 & 7\end{array}$

\subsection{STRATEGIC PLANNING}

a. We have a mission statement which has been communicated throughout the plant and is supported by our staff

b. We have a written statement of strategy covering all operations, which is clearly articulated and agreed to by our senior plant staff

c. Our plant's operations are effectively aligned with the corporate business mission.

d. Our plant has a formal strategic planning process which results in a written mission, long-range goals and strategies for implementation

e. Plant management routinely reviews and updates a long-range strategic plan

$\begin{array}{lllllll}1 & 2 & 3 & 4 & 5 & 6 & 7 \\ 1 & 2 & 3 & 4 & 5 & 6 & 7 \\ 1 & 2 & 3 & 4 & 5 & 6 & 7 \\ 1 & 2 & 3 & 4 & 5 & 6 & 7 \\ 1 & 2 & 3 & 4 & 5 & 6 & 7\end{array}$

\subsection{TRAINING}

a. Employees receive training to perform multiple tasks

b. Employee flexibility, multi-skilling and training are actively used to support improved performance

c. Ongoing education and training for all employees is encouraged

d. Top management is committed to employee training

e. We have a plant-wide training and development process, including career path planning, for all our employees

$\begin{array}{lllllll}1 & 2 & 3 & 4 & 5 & 6 & 7 \\ 1 & 2 & 3 & 4 & 5 & 6 & 7 \\ 1 & 2 & 3 & 4 & 5 & 6 & 7 \\ 1 & 2 & 3 & 4 & 5 & 6 & 7 \\ 1 & 2 & 3 & 4 & 5 & 6 & 7\end{array}$

2.4. EMPLOYEE INVOLVEMENT
a. Cross-functional teams are often used
b. During problem solving sessions, we make an effort to get all team members' opinions and ideas before making a decision
c. All employee suggestions are evaluated

$\begin{array}{lllllll}1 & 2 & 3 & 4 & 5 & 6 & 7 \\ 1 & 2 & 3 & 4 & 5 & 6 & 7 \\ 1 & 2 & 3 & 4 & 5 & 6 & 7\end{array}$



d. There is increased employee autonomy in decision-making

$\begin{array}{llllll}2 & 3 & 4 & 5 & 6 & 7 \\ 2 & 3 & 4 & 5 & 6 & 7 \\ 2 & 3 & 4 & 5 & 6 & 7\end{array}$
e. Our staff are empowered to make decisions
f. In the past 3 years, many problems have been solved through small group sessions

\subsection{INFORMATION AND FEEDBACK}

$\begin{array}{lllllllll}\text { a. } & \text { Important data are presented and communicated to employees } & 1 & 2 & 3 & 4 & 5 & 6 & 7 \\ \text { b. } & \text { Charts showing plant performance are posted on the plant floor } & 1 & 2 & 3 & 4 & 5 & 6 & 7 \\ \text { c. } & \text { We make use of benchmarking data } & 1 & 2 & 3 & 4 & 5 & 6 & 7 \\ \text { d. } & \text { Information on productivity is readily available to employees } & 1 & 2 & 3 & 4 & 5 & 6 & 7 \\ \text { e. } & \text { We collect and analyse information on our important activities } & 1 & 2 & 3 & 4 & 5 & 6 & 7 \\ \text { f. } & \text { We have easy access to the information we need } & 1 & 2 & 3 & 4 & 5 & 6 & 7\end{array}$

\subsection{PLANNED MAINTENANCE}
a. We emphasize reliability maintenance as a strategy

$\begin{array}{lllllll}1 & 2 & 3 & 4 & 5 & 6 & 7 \\ 1 & 2 & 3 & 4 & 5 & 6 & 7\end{array}$
b. Preventive maintenance is widely practiced in our plant
c. Operating, maintenance, and technical personnel are fully involved in doing root cause analysis
d. Records of maintenance are kept
e. Our plant has established a total preventive maintenance programme

$\begin{array}{lllllll}1 & 2 & 3 & 4 & 5 & 6 & 7 \\ 1 & 2 & 3 & 4 & 5 & 6 & 7 \\ 1 & 2 & 3 & 4 & 5 & 6 & 7\end{array}$

\subsection{OPEN CULTURE}
a. We have a flat hierarchical organizational structure
b. Our operation decisions are detailed in formal written reports
c. We have a more open, trusting organizational culture
d. In our plant there is less bureaucracy
e. We often make use of empowered work teams
f. There is increased staff autonomy in decision-making

$\begin{array}{lllllll}1 & 2 & 3 & 4 & 5 & 6 & 7 \\ 1 & 2 & 3 & 4 & 5 & 6 & 7 \\ 1 & 2 & 3 & 4 & 5 & 6 & 7 \\ 1 & 2 & 3 & 4 & 5 & 6 & 7 \\ 1 & 2 & 3 & 4 & 5 & 6 & 7 \\ 1 & 2 & 3 & 4 & 5 & 6 & 7\end{array}$

\subsection{PEOPLE MANAGEMENT}

a. The concept of the "internal customer" is well understood at this plant $\quad \begin{array}{llllllllll} & 1 & 2 & 3 & 4 & 5 & 6 & 7\end{array}$

b. Our site has effective "top-down" and "bottom-up" communication $\quad \begin{array}{lllllllll} & 2 & 3 & 4 & 5 & 6 & 7\end{array}$

c. Employee satisfaction is formally and regularly measured $\quad \begin{array}{lllllllll} & 1 & 2 & 3 & 4 & 5 & 6 & 7\end{array}$

d. Our Occupational Health and Safety practices are excellent $\quad \begin{array}{lllllllll} & 2 & 3 & 4 & 5 & 6 & 7\end{array}$

e. $\quad$ Reward and recognition systems support the plant's performance objectives $\quad \begin{array}{llllllllll}1 & 2 & 3 & 4 & 5 & 6 & 7\end{array}$

$\begin{array}{llllllllll}\mathrm{f} . & \text { We have internal promotion of staff } & 1 & 2 & 3 & 4 & 5 & 6 & 7\end{array}$

\subsection{CUSTOMER FOCUS}
a. We know our external customers' current and future requirements

$\begin{array}{lllllll}1 & 2 & 3 & 4 & 5 & 6 & 7 \\ 1 & 2 & 3 & 4 & 5 & 6 & 7\end{array}$
b. We strive to be highly responsive to our customers' needs 
C. We regularly measure external customer satisfaction

d. We are customer focussed

e. Customers' complaints and problems are resolved promptly and efficiently

f. Our company actively seeks ways to meet customers' requirements

$\begin{array}{lllllll}1 & 2 & 3 & 4 & 5 & 6 & 7 \\ 1 & 2 & 3 & 4 & 5 & 6 & 7 \\ 1 & 2 & 3 & 4 & 5 & 6 & 7 \\ 1 & 2 & 3 & 4 & 5 & 6 & 7\end{array}$

\subsection{PLANT PERFORMANCE}

For question (1) below, please circle the number which best describes your plant's PRESENT position:

1 = "Strongly disagree", 2 = "Moderately disagree", 3 = "Mildly disagree", 4 = "Neither agree nor disagree", $5=$ "Mildly Agree", 6 = "Moderately agree" and 7 ="Strongly agree"

1. Over the past three years, ...

Strongly disagree Strongly agree

a. $\quad$.... our plant has high success in meeting anti-pollution targets

b. .....our plant unplanned outage rate is low

C. $\quad$.....our plant's unit cost of production has decreased

d. $\quad$......we have reduced the number of unit trippings

e. $\quad$.....our industrial safety record is excellent

f. $\quad$....we have put in place measures in our plant that always exceed or meet environmental requirements

g. .... our plant was "accident-free"

h. .....our relationship with our neighbourhood community is excellent

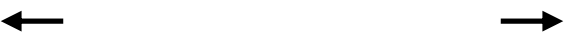

i. $\quad$....our plant production of electricity has increased

$\begin{array}{lllllll}1 & 2 & 3 & 4 & 5 & 6 & 7 \\ 1 & 2 & 3 & 4 & 5 & 6 & 7 \\ 1 & 2 & 3 & 4 & 5 & 6 & 7 \\ 1 & 2 & 3 & 4 & 5 & 6 & 7 \\ 1 & 2 & 3 & 4 & 5 & 6 & 7 \\ 1 & 2 & 3 & 4 & 5 & 6 & 7 \\ 1 & 2 & 3 & 4 & 5 & 6 & 7 \\ 1 & 2 & 3 & 4 & 5 & 6 & 7 \\ 1 & 2 & 3 & 4 & 5 & 6 & 7\end{array}$

2. Please indicate your plant's current performance level for EACH of the indicators by writing down a single number, ranging from 1 through 7 , in the vacant end column.

\begin{tabular}{|l|l|c|c|c|c|c|c|c|c|}
\hline & Indicators & $\mathbf{1}$ & $\mathbf{2}$ & $\mathbf{3}$ & $\mathbf{4}$ & $\mathbf{5}$ & $\mathbf{6}$ & $\mathbf{7}$ & $\mathbf{( 1 - 7 )}$ \\
\hline A & $\begin{array}{l}\text { Average annual plant capacity factor \% for the } \\
\text { past three financial years }\end{array}$ & $<10$ & $11-20$ & $21-40$ & $41-60$ & $61-80$ & $81-95$ & $>95$ & \\
\hline B & $\begin{array}{l}\text { Average annual Plant Equivalent Availability } \\
\text { factor \% for the past three financial years }\end{array}$ & $<50$ & $51-60$ & $61-70$ & $71-80$ & $81-90$ & $91-95$ & $>95$ & \\
\hline
\end{tabular}




\subsection{RESPONDENT'S PARTICULARS}

Finally we would like to end by asking a few bits of information about yourself so that we can put your other replies in greater context.

1. Years of service in this power plant/site:

2. Years of work experience in power sector:

3. Please indicate your position (or job title) within your power plant

4. Your comments, if any 